NASA Technical Memorandum 101392

\title{
Applications of Surface Analysis and Surface Theory in Tribology
}

(NASA-TE-101392) APPLICATIOSS CP SORFACE

\section{$\begin{array}{ll} & \text { Onclas } \\ 63 / 23 & 0188848\end{array}$}

John Ferrante

Lewis Research Center

Cleveland, Ohio

Prepared for the

Fifth International Conference on Quantitive Surface Analysis sponsored by the National Physical Laboratory

London, England, November 15-18, 1988 
APPLICATIONS OF SURFACE ANALYSIS AND SURFACE THEORY IN TRIBOLOGY

John Ferrante

National Aeronautics and Space Administration

Lewis Research Center

Cleveland, Ohio 44135

\section{SUMMARY}

Tribology, the study of adhesion, friction and wear of materials is a complex field which requires a knowledge of solid state physics, surface physics, chemistry, material science and mechanical engineering. It has been dominated, however, by the more practical need to make equipment work. With the advent of surface analysis and and advances in surface and solid state theory a new dimension has been added to the analysis of interactions at tribological interfaces. In this paper the applications of surface analysis to tribological studies and their limitations will be presented. Examples from research at the National Aeronautics and Space Administration's Lewis Research Center will be given. Emphasis will be on fundamental studies involving the effects of monolayer coverage and thick films on friction and wear. A summary of the current status of theoretical calculations of defect energetics will be presented. In addition, some new theoretical techniques which enable simplified, quantitative calculations of adhesion, fracture and friction are discussed.

\section{INTRODUCTION}

Tribology, the science of surfaces in contact with relative motion, is a field with considerable technological importance. In spite of its importance there is still no complete understanding of mechanisms. This in part due to the range and complexity of the subject, involving many material combinations, lubricants, mechanical and material properties and chemical interactions. ${ }^{1-8}$ Surface analysis is an important component in tribology since interfacial forces and material properties ${ }^{9,10}$ are determined by the composition of the interface. For example, most liquid lubricants are composed of some base oil plus additives. The reaction of these materials with the substrate and the shear in these films determines the friction and wear properties of the materials. However, these reactions and interfacial material properties are not well characterized and understood. Consequently, there is a substantial task involved in simply analyzing the composition of such interfaces both from a surface reaction standpoint and a mechanically induced reaction standpoint.

The present paper attempts to outline the types of experiments in 
tribology where surface analysis is of interest. Examples range from lubricated contacts to the effects of monolayer adsorption. These examples will come primarily from research performed at the National Aeronautics and Space Administration Lewis Research Center's Surface Science and Tribology Branch and are not meant to represent a comprehensive review of the literature. The emphasis is to relate friction and wear to reactions at and composition of the interface. A summary of the current state of surface theory as applied to tribology will also be presented.

\section{I. BACKGROUND}

As was stated in the introduction the purpose of this paper is to provide a background for where surface analysis is needed in tribology. We start by defining the material systems of interest. The materials involved in tribology span the entire range; metals, ceramics, polymers and all combinations of these in contact with one another. In addition to dry contacts most often there are intervening lubricating films both liquids such as oils or solid lubricating films such as molybdenum disulfide. The liquids often have chemical additives and the solids may be heterogeneous mixtures whose properties vary with extremes of temperature or pressure. Accompanying the complexity of material combinations we have the additional complexity resulting from mechanical deformations, adhesion, wear and chemical interactions at the interface.

Wear is usually the critical parameter in engineering applications rather than friction. Wear can arise from a number of mechanisms such as adhesion, breaking of bonds in the weaker material by stronger interfacial forces, cyclic fatigue, defect accumulation or corrosion. The most important function of the lubricant, therefore, is to lessen the wear process by preventing contact between the solid surfaces or providing a medium which shears more easily. Friction is an important operational parameter which can determine efficiency but is not the important life limiting property. For a specific application you may want either high or low friction and it may not necessarily correlate with wear, for example, one may have high corrosive wear but low friction.

In lubricated contacts three regimes are usually defined, hydrodynamic lubrication, elastohydronamic lubrication, and boundary lubrication ${ }^{11}$. The 
physical mechanisms in these regimes also elucidate the problems involved in dry sliding or sliding with solid films. In hydrodynamic lubrication the lubricant is forced through a convergent gap, develops a pressure and prevents contact between the surfaces. The design parameter is to obtain a film of sufficient thickness to prevent asperity contact. In this case failure is caused by an accidental contact or scuff which leads to the generation of a wear particle. Also the cyclic fatigue process mentioned above can lead to the generation of a wear particle. Often additives are included in the lubricant to protect the surfaces from severe wear during a scuff. A more subtle consideration is the zero flow at the lubricant solid interface. The strength of the bond of the lubricant at the interface as compared to the shear forces in the film are a topic of interest 11,12

The second regime, elastohydrodynamic lubrication, occurs with decrease fluid viscosity or increased load. Under these circumstances the film thickness decreases. If the thickness decreases sufficiently the the asperities can penetrate the film and solid-solid contact may occur. However, under these conditions high contact pressures cause an increase in the lubricant viscosity to the point depending on temperature that it behaves like an elastic solid and is somewhat akin to a solid lubricant. Again analysis of the composition of these films combined with friction and wear studies would be of interest.

Finally, when either the pressure is very high or the speed is low the lubrication is described as boundary lubrication. For this situation solid-solid contact is assured and either reaction films or mono - molecular films provide the wear protection. Boundary lubrication provides the most accessible regime for surface analysis. Surface modification is another topic which should be mentioned. By this we mean deposition of hard or soft films by techniques such as sputter deposition or the modification of surface properties by ion-implantation. In either case analysis of the surface region and its correlation with tribological properties are of interest.

\section{PROBLEMS AND GOALS}

After establishing the need for analysis of conditions accompanying contacts we should discuss some of the problems facing the surface scientist in studying tribological systems. The principal interests are to determine 
the effect of interface composition on wear, adhesion and friction. The first difficulty is that in situ analysis is not possible in most cases, since the region of interest is in the contact. Consequently, inferences must be made from examining the surfaces before and after contact. A second is that the mechanical contacts may promote reactions that would not be observed in static studies, such as, adsorptions experiments. Also, engineering surfaces are not flat. Hollow regions may trap lubricants and reaction films may represent only a small fraction of the area at the asperity tips. Thus, it is desirable to have a scanning capability in order to distinguish between active and passive regions. In addition, care must be taken not to remove the important component in the cleaning procedure by solvents to prepare the materials for surface analysis, e.g. a polymer film formed by high pressure in the contact. In general, a multiplicity of analytical tools are desirable which give elemental, chemical and depth compositional analysis.

Finally two distinctions concerning approach should be made, which will be classified as practical tribology and fundamental tribology. By practical tribology, we mean analysis of actual working components, such as, performing post failure analysis. We define fundamental tribology as dedicated to determining underlying physical mechanisms. Fundamental tribology involves a broader perspective than most fundamental studies in that it spans experiments ranging from ultrahigh vacuum to "dirty" experiments in lubricated systems. In tribology the fundamental studies should be emphasized. First, practical studies are often too specific with conditions too ill defined to reveal any general mechanisms. At this point there isn't a sufficient data base obtained under well controlled conditions to develop theoretical models for fundamental tribology. Only continuum mechanics of deformations and continuum fluid flow are reasonably well understood. Material scientists and solid state physicists are only in the early stages of attacking problems of interest in tribology. The complexities of practical tribology make theoretical modeling for it unlikely in the near future. Now we proceed to give examples of experimental studies with an emphasis on the relationship to surface analysis and examples of the current state of surface theory as applied to tribology.

\section{APPLICATIONS OF SURFACE ANALYSIS IN TRIBOLOGY}


In this section we give examples of dirty systems where surface analysis has been used to analyze the results of wear experiments and then proceed to some more fundamental studies. The first example is for a lubricated contact in a pin on disk aparatus ( $f i g .11$ ). The pin on disk is a simple friction and wear apparatus often used in tribology. A pin with a hemispherical tip is placed on a rotating disk. Pin wear is determined by measuring the diameter of the wear scar, height change or weight change. Disk wear is determined by the change in wear groove dimensions or weight change. The friction force is determined by strain gauges. The experimental difficulties involved with such measurements are apparent. In fig. 1 we show the apparatus mounted in an ultra-high vacuum system. A typical method to represent the data is to plot rider wear in $\mathrm{cm}^{3}$ versus versus sliding distance or time (fig. 2). This curve shows two regions a "run-in" portion then a steady state portion. Fig. 3 shows the results of two Auger electron spectroscopy (AES) depth profiles of a pure iron pin on a hard tool steel disk for wear in the steady state region. The materials were selected to guarantee high rider wear. The lubricant base stock was dibutyl sebacate with one weight percent zinc-dialkyl-dithiophosphate (ZDDP) ${ }^{13,14}$. From figs. $3 a$ and $3 b$ we see that the sulfur in the additive formed a reaction layer. Fig. 3a show that the oxygen in the dry air ambient reacted to form iron-oxygen-sulfur compounds, whereas with a dry nitrogen ambient we only have evidence for iron-sulfur compounds. In fig. 4 we show the wear rate for the family of lubricants associated with dibutyl sebacate. There are a number of interesting features. The wear rate depends on the base stock as well as the additive. In some base lubricants wear was decreased with addition of the ZDDP and in others it was not. The oxalate plus additive gave very high wear which we concluded was due to corrosive wear by inspection and AES analysis of the pin. With the sebacate we see that the atmospheric oxygen is important in reducing wear as compared to the nitrogen ambient whereas the additive seemed to promote it. In nitrogen the additive reduces wear. This could be due to the nature of shear in the surface film formed. These results demonstrate the complexities and the number of conditions which must be controlled when performing wear studies.

A second example of a pin on disk experiment showing additive effectiveness is given in fig. $5^{15}$. In this 4.25 volume percent tricresyl 
phosphate (TCP) is dissolved in a base stock of trimethyal propane triheptanoate (TMPTH), a synthetic lubricant used as a standard in tribological experiments. Fig. 5 shows a step loading curve in which wear rate obtained from the slope of the wear versus sliding distance curve is plotted versus load. It shows that the addition of additive greatly reduces the wear rate until some load is reached where the film giving the wear resistance is penetrated. This result is different from the previous result with ZDDP in that surface analysis shows no thick film (fig. 6). The depth profile is characteristic of an adsorbed film. The AES spectrum shows evidence of a phosphate formation but no differences were found between the low wear regions and the failure region. This result leads to several possible mechanisms. This is a true monolayer effect, shear removes a loosely bound film or the solvent cleaning solution for surface analysis has removed the important wear reducing film e.g. a friction polymer. Several attempts to establish the latter failed but that possibility is still open to question. In any event the wear reduction occurs by a different mechanism from the ZDDP.

We now show a dry sliding result for the pin on disk apparatus shown in fig. $1^{16}$. In this experiment softer iron, nickel and cobalt riders were slid on refractory disks of tungsten, tantalum, molybdenum and niobium. The results are summarized in table $I$. The surprising result is that transfer occurred in all cases with a tungsten disk or with a cobalt rider. No transfer of iron or nickel were observed to the other hard metals. This can be explained in terms of the mechanical properties of the materials. Tungsten is hardest of the materials. Nickel and iron strain harden thus minimizing deformation and transfer. Cobalt which has a hexagonal close packed structure has easy slip planes. Thus the simple answer concerning direction of transfer based on cohesive and interfacial energies is complicated by changes in mechanical properties of the materials involved.

There has been considerable interest lately concerning surface modification by ion-implantation in order to reduce wear ${ }^{17}$. In $\mathrm{fig}$. 7 we show the results of a depth profile of a pure iron pin implanted with nitrogen at $1.5 \mathrm{MeV}$ and a dose of $5 \times 10^{17}$ atoms $/ \mathrm{cm}^{2}$. A comparison with range theory gave good agreement with the observed distribution. It was found that wear of the iron was reduced by 40 percent in the run-in region and 20 percent in the steady state region of the wear curve (fig. 2) with a 95 
percent confidence level. The pin on disk experiment is some what ambiguous in this study in that only an anulus on the edge of the wear scar remains implanted once wear is beyond the depth of implantation at the center. An analysis of the geometry indicated that wear was only reduced in the implanted region. Consequently, there was no evidence for wear reduction beyond the range of implantation. It is for this reason that the 40 percent reduction in the run-in region was considered to be the significant test.

As a further example of "dry sliding", results are presented for hard coatings ${ }^{18}$ which are of interest because of their high hardness and ability to withstand high temperatures. In fig. $8 \mathrm{a}$ we show the wear and friction for $\mathrm{Mo}_{2} \mathrm{C}$ radio frequency $(R F)$ sputtered onto a $440 \mathrm{C}$ disk under three conditions; zero biased and etched, a $(-300 \mathrm{~V})$ bias with two minutes holding period and a preoxidized disk with a zero bias. The zero biased coating gave poor friction and wear whereas the films with a bias gave lower friction and wear. An etched film with a bias and no holding period gave poor adhesion. In figs. $8 b$ and $8 c$ we show X-ray photoemission spectroscopy (XPS) depth profiles of the three conditions. For no bias the film is a mixture of carbides and oxides. The biased pretreated films have similar compositions with carbides as the outer layer, but a transition oxide at the interface. The improved wear is dependent on having the carbide surface whereas good adhesion seems to require the transition oxide. Therefore, the friction and wear properties can be correlated with the composition of the films as obtained from surface analysis. It should be pointed out that soft films such as molybdenum di-sulfide ${ }^{19}$ lubricate by a shear in the film, a mechanism similar to liquid lubricants. Hard coatings have application in the cutting tool industries and decorative coatings industries.

The discussion of dry sliding is concluded with polymer transfer studies. The transfer of polytetrafluoro-ethylene (PTFE), polyvinyl-chloride (PVC) and perchloro-tri-fluoroethylene (PCTFE) to S-monel, a nickel, copper, silicon alloy, with high hardness is presented ${ }^{20}$. These materials were selected since the halides are easily detected by AES. The AES spectra after sliding are shown in fig. 9. The PTFE (fig. 9a) spectrum stabilizes after a few passes to an estimated film thickness of 3 to 5 layers based on the attenuation depth with AES. The larger flourine and smaller carbon obtained with moving the sample under the beam indicates decomposition of the transferred film. The friction coefficient was less than 0.1 and there was 
no evidence of stick-slip motion. PVC behaved very differently during sliding. The AES spectrum ( $f i g .9 b$ ) shows a large chlorine peak and small attenuation of the metal peaks and no evidence of electron impact desorption (EID). These results suggest a decomposition of the PVC resulting in chlorine adsorption and no polymer transfer film formation. The friction coefficient decreased from 0.5 to 0.3 during run-in. Finally, PCTFE has an AES spectrum similar to PVC ( $f$ ig. 9c) in that there was a large chlorine peak was stable, but the flourine showed EID and stability with rotation of the disk. The attenuation of the metal peaks is between PTFE and PVC. The results are less certain in this case. They suggest that chlorine is chemisorbed, but that there may be a patchy monolayer transfer film formed. The friction coefficient was again rather high, 0.4 , with appreciable stick-slip. The PTFE results fit previous models proposed by Pooley and Tabor 21 in which the end of the PTFE chain bonds to the metal and is drawn out of the bulk giving finally PTFE sliding on PTFE leading to low friction. Such transfer films are important in prosthesis ${ }^{22}$. For PVC and PCTFE there was evidence for decomposition and for PCTFE forming patchy transfer films. PVC and PCTFE also had bits of metal embedded in the plastic indicating some shear in the bulk of the metals.

\section{EVIDENCE FOR MONOLAYER EFFECTS}

The next question to be addressed is what evidence is there for monolayer effects in the friction force? This point does not question their existence, but rather whether they can be detected with the gross mechanical deformations taking place during sliding or contact. We proceed to give some examples where monolalyer effects are apparent.

Wheeler ${ }^{23}$ has used static friction experiments to investigate the effect of adsorbates on metals ( $f$ ig. 10). These were performed by loading a metal pin against a metal flat and measuring the force needed to initiate sliding which is equivalent to measuring the static friction force. The effects of adsorption of partial monolayers of oxygen and chlorine on the surface were examined. The experiments were performed in an ultrahigh vacuum system with AES for characterization. Several metals were used: copper, iron and steel. In all of these cases there seem to be no difference in the effects of oxygen 
or chlorine at partial monolayer coverages if atomic size is included. Adsorption reduced the static friction in all cases. These results can be interpreted quantitatively in terms of a junction-growth model ${ }^{1}$ where clean metal is exposed during sliding. For metals, Wheeler's results show that there is a decrease in friction with adsorption of oxygen or chlorine at partial monolayer coverages on both surfaces. At this point there is no conclusion for what will happen if adsorption occurs on only one of the surfaces.

Pepper has examined the effects of adsorbates on metal-insulator contacts $^{24}$. The experimental apparatus for static friction or interfacial shear measurements consists of a metal ball on an insulating flat. Pepper observed a difference in static friction coefficient between sapphire and clean metal depending on the metal. For example, silver gave a low interfacial shear stress as compared to iron (fig. 11). Furthermore, adsorption of partial monolayers on the metal surface also changed the coefficient of static friction. In addition, the direction of the change in static-friction was adsorbate dependent. Adsorption of oxygen on nickel or copper increases the static friction coefficient with single crystal sapphire, whereas chlorine decreases it (fig. 12). Ethylene also increases the shear strength slightly, and nitrogen decreases it slightly. The same effects occurred on nickel and copper which are metals with different properties. Copper does not readily adsorb oxygen. These results show that there are partial monolayer effects on the shear force for metal sapphire contacts.

Another example of similar results can be found in Pepper's work on diamond ${ }^{25}$. The diamond surface is known to be terminated by hydrogen. Pepper found that the hydrogen could be removed by either electron bombardment or heating in an ultrahigh vacuum system. Following either treatment, an extra feature appears in the electron energy loss spectrum (fig. 13) that can be identified as extra states appearing in the band gap. If the converted surface is exposed to dissociated hydrogen, the extra states disappear from the energy loss spectrum. The low energy electron diffraction (LEED) pattern changes from a $1 \times 1$ to a $1 \times 2$ pattern on removal of the hydrogen. The 
interesting feature is that these changes can also be observed in the static friction coefficient (fig. 14). The coefficient of static friction with a metal ball is low before the conversion occurs. Following conversion the friction coefficient increases, therefore, changes in the electronic state and structure of the surface are detected in the friction coefficient. Readsorbing the hydrogen returns the friction coefficient to its original lower value. These results correlate well with additional features occurring the energy loss spectrum, such as core level valence band excitations. Desorption experiments of hydrogen give binding energies that were comparable to removal of hydrogen from methane. As further evidence, XPS shows the the surface becomes conducting when the hydrogen is removed. The XPS carbon peakfollows a bias voltage after the surface transformation, but does not prior to the transformation. We thus have a remarkable result, the surface is altered and these changes are detected in the macroscopic static friction measurements.

It is of interest to see if these effects can be observed in a dynamic friction experiment. The sliding friction results in a pin on disk apparatus in an ultrahigh vacuum system are rather remarkable 26 (fig. 15). Oxygen adsorbed on a metal disk in contact with a sapphire pin increases the dynamic friction coefficient. When the oxygen is removed and the layer is worn away the friction coefficient returns to its original value. Chlorine has the opposite effect, it lowers the friction force. Visual examination of the wear track on the disk shows severe roughening of the surface. The dramatic result is that a surface effect was detected in spite of a macroscopic roughening of the surface.

As a final example of such results the dynamic friction coefficient of an alumina sphere on an amorphous alloy, 67Fe-18Co-14B-1Si, was examined as a function of temperature 27 . Fig. 16 shows the coefficient of friction as a function of temperature of the alloy. The samples were heated, loaded and then translated. As would be expected from mechanical considerations, the friction coefficient increases with temperature, however, between $350 \mathrm{C}$ and 
$500 \mathrm{C}$ there is dramatic decrease. The XPS spectrum for the alloy after heating to various temperatures (fig. 17) indicates a change in surface composition after heating. Consequently, there is evidence that surface alteration obtained with segregation of partial monolayer coverages can affect interfacial forces macroscopically.

VI. THEORETICAL CONSIDERATIONS

Surface and bulk solid state theory for describing interfacial forces are only in their initial stages. At this point only Ferrante and $\mathrm{Smith}^{28}$ have attempted to model adhesion in detail at clean metal interfaces. They calculated the binding energy as a function separation using a quantum mechanical jellium model for a number of simple metals in contact (fig.18). They found that the strong bonding force had a range of an interplanar spacing and that the interface could have a binding force stronger than the cohesively weaker of the two materials. A point subject only to speculation before this work. Smith et al ${ }^{29}$ have calculated the binding energy at transition metal interfaces with a more complete quantum mechanical formalism. Rose, Smith and Ferrante ${ }^{30}$ found that the adhesive binding energy scaled onto one another thus giving a single shape. These points will discussed in more detail later.

Most techniques in solid-state calculations rely on the periodicity of the lattice to simplify the calculations ${ }^{31}$. This periodicity is lost at interfaces, consequently special approaches are needed. The theoretical models used depend on the materials comprising the interface. For example, at free-electron metal interfaces, binding may not be localized, whereas at transition metal, semiconductor or ceramic interfaces, we might expect localized bonding to be important. Pair potentials are often used to represent nonmetals ${ }^{32}$. In this method, the interaction between atoms is approximated by some two-body potential, e.g., a Van der Waals potential, and the energetics are obtained by establishing the geometry of the defect and summing over two-body interactions. For metals, this approach is not sufficient, because of the mobility of the electrons which redistribute their positions in the vicinity of a defect. Smith and Ferrante 33 have estimated this electron redistribution contribution to the grain boundary energy for simple metals and have shown it to be large compared to pair potential 
contributions. There are attempts to include these volume-dependent contributions into pair potential calculations ${ }^{34}$, however a question arises concerning how well these represent complicated defect structures. Another quantum mechanical approach used for these situations involves Green's function $^{35}$ or tight-binding methods ${ }^{36,37}$. These approaches have been used recently to calculate grain boundary energies in semiconductors.

Fully quantum mechanical calculations of interfacial energies $38,39,40$ with self-consistency are quite complicated and require substantial computer time. Defects are included by constructing super cells using periodic boundary conditions. In order to examine relaxation, which occurs in most defect structures, it is necessary to repeat the calculations many times for different structures, in order to search for energy minima. This further adds to complexity of the problem. Applying such techniques with molecular dynamics in order to include dynamic or temperature effects further complicates the calculations. Recently, Car and Parrinello 41 have developed a technique to optimize the search for energy minima, but the procedure still remains quite complex. Thus for the non-specialist it would be useful to develop semi-empirical techniques for calculating defect energetics which have the simplicity of pair potentials but include the volume-dependent effects. We address this topic shortly but first we will give a more detailed discussion of the results of Ferrante, Rose and Smith.

These calculations used a one-dimensional jellium model corrected for three-dimensional effects. The adhesion energy was defined as

$$
E_{A D}=\frac{E(a)-E(+\infty)}{2 A}
$$

where $E$ is the total energy of the system, $a$ is the separation distance between the surfaces of the two metals and $A$ is the cross-sectional area. The results of this calculation for the high-density surfaces of a number of simple metals in contact are shown in fig. 18. Relaxation was not included this calculation, with both materials frozen at their bulk structures. We 
see that the binding curves have the general shape expected. The strength of the interfacial bond was quite high, comparable to surface energies of the bulk materials, and the range was of the order of interplanar spacings. Rose, Smith and Ferrante found that these curves scaled (fig. 19) i.e. the energy could be written in a form

$$
E=\Delta E E^{*}\left(a^{*}\right)
$$

where $a^{*}=\left(r-r_{e}\right) / 1, \Delta E$ is the binding energy, $r_{e}$ is the equilibrium separation, and 1 is a scaling length determined from the binding energy and the second derivative of the binding energy at equilibrium and $E^{*}\left(a^{*}\right.$ ) is some universal function. This scaling is more general than might first be anticipated, and in fact the scaling applied to a wider class of phenomena. In fig. 20, we show the results for scaling cohesive energies for a transition metal, bimetallic adhesion, chemisorption and a diatomic molecule.

Thus there is some underlying simplicity in certain types of binding.

These results lead us finally to the discussion of the semi-empirical techniques needed to model interfaces and defects. The first technique is the embedded atom method of Foiles, Daw and Baskes 42 In this procedure the energy required to embed an ion in a jellium is considered. The total energy is written in the form

$$
E=F(n)+(1 / 2) \Sigma_{i, j} z_{i}\left(r_{i j}\right) z_{j}\left(r_{i j}\right) / r_{i j}
$$

$F(n)$ is called the embedding energy where, $n$, is the electron density, and the second term represents the pair repulsion between ion cores, where $Z$. is the valence and $r$ is the distance between ions. In its most recent form, the "universal" binding energy relation of Rose, Smith and Ferrante is used to define the embedding energy for the cohesive energy case. The electron density is obtained from overlapping atomic densities. Once the embedding function is obtained, it is applied to a defect, such as a surface, by overlapping the atomic densities and using the embedding function for the given material, along with the pair repulsion term to obtain the energy with a defect. Fig. 20 shows the results of applying this technique to determine the adhesion energy for three planes of nickel. The results give the correct trends, are for transition metals, are fully three dimensional and are substantially easier to obtain than the earlier method used by Ferrante and Smith. 
The next method we wish to describe is the equivalent crystal method of Smith and Banerjea ${ }^{43,44}$. This technique also uses the universal binding energy relation. An ion in a defect is represented by an ion in a perfect crystal with a structure the same as the bulk material. Perturbation theory is applied to the difference between the ion in the defect and the ion in the equivalent crystal, giving

$$
E=\Delta E E^{*}\left(a^{*}\right)+E_{1}+E_{2}+E_{3}+\ldots
$$

where the first term represents the energy of the atom in the crystal, and the rest of the terms represent the differences in the ion core-ion core interaction, valence electron kinetic energy, valence electron-ion core interaction, and valence electron-valence electron interaction between the crystal and the solid with defects. The problem is solved by picking the Wigner-Seitz radius used in defining the distance in $a^{*}$ to make the higher order terms in the perturbation expansion disappear. With this accomplished, only the first simple term need be evaluated. Smith and Banerjea have used the method to accurately predict surface energies to an error of less than 10 percent compared to the full quantum mechanical calculations. We note that experimental surface energies are extremely difficult to measure and reliable to only plus or minus 20 percent at best. Smith and Banerjea have altered the model slightly to include a bond compression term in order to include surface relaxation and predicted the relaxation in the spacing between surface planes to high acccuracy. These results are particularly impressive, since they represent small energy differences. These are very difficult to obtain from the fully quantum mechanical calculations. It is necessary to extend this method to a wider class of materials. This extension and application to a wider class of defects is in progress. We point out that the fully quantum 
mechanical calculations are still needed, since many properties cannot be calculated with the semi-empirical methods and also as a test of the semi-empirical methods. Both this method, and the embedded atom method, are simple enough to treat relaxation problems.

The current status of solid state theory is not sufficient to describe the complexities involved in tribology. The methods described do not directly describe friction. These methods involve conservative processes whereas friction is non-conservative. Two methods for describing these loss mechanisms within the framework discussed come to mind. First to explain the thermal losses, one could use molecular dynamics, in fact, such efforts are currently progress ${ }^{45}$. The other losses involve defect formation and plastic deformation of the solid which can be included into the methods described. The problems are that any real experiment even those characterized as fundamental is quite complex from the theoreticians stand point considering the many material combinations and defect mechanisms. As emphasized earlier there isn't a sufficient data base from which to perform theoretical modeling. At best trends can be predicted at present. It is necessary to perform careful experiments with force measurements combined with accurate structural and chemical characterization. Simple experimental systems must be selected along the lines of Wheeler's and Pepper's in order to provide the needed characterization.

\section{CONCLUDING REMARKS}

The purpose this paper has been to present problems in tribology that should be adressed by surface scientists. At present there are great opportunities for careful research which can elucidate physical mechanisms. There are two categories for the research. The first is the design of simple experiments which can be used for the solid state theorist for modeling, such as, the atomic force microscope. The second is to attack the more complex mechanisms such as lubricated contacts, additives, solid lubricants in order to act as a guide when theory catches up with experiment and to give a better understanding of mechanisms to designers of equipment. Even in the more complex experiments there is a need to limit the scope in order to have strict control of the many variables involved. At present there is a great 
need for carefully controlled and focused research.

\section{REFERENCES}

1. D.H. Buckley, Surface Effects in Adhesion, Friction, Wear and Lubrication, Elsevier, Amsterdam, 1982

2. F. P. Bowden and D. Tabor, The Friction and Lubrication of Solids, Oxford University Press, Oxford, 1950

3. F. P. Bowden and D. Tabor, The Friction and Lubrication of Solids II, Oxford University Press, Oxford, 1964

4. D. Tabor, Surface Physics of Materials Vol. II, Chapl 10, J. M. Blakely ed., Academic Press, New York, 1975

5. D. Tabor, J. Lubrication Technology 99, 387 (1977)

6. D. Tabor, J. Lubrication Technology 103, 169 (1981)

7. D. R. Wheeler, Scanning Electron Microscopy/1981/ II, 589 (1984)

8. D. H. Buckley, J. Ferrante, M. D. Pashley and J. R. Smith, Materials Science and Engineering 83, 177 (1986)

9. J. Ferrante, Opportunities and Research Needs in Adhesion Science and Technology, B. B. Fuller and K. L. Mittal eds., National Science Foundation grant no. CBT-87-02200, 4-1 (1988)

10 J. Ferrante, G. H. Bozzolo, C. W. Finley and A. Banerjea, Mat. Res. Soc. Symp. Proc. 119, 3 (1988)

11. D. Tabor, Microscopic Aspects of Adhesion and Lubrication, Tribology Series 7, J. M. Georges ed., 651 Elsevier, 1982

12. J. N. Israelachvilli, P. M. McGuiggan and A. M. Homola, Science 240, 189 (1988); Science 241, 795 (1988)

13. W. A. Brainard and J. Ferrante, NASA TP-1544, (1979)

14. W. A. Brainard and J. Ferrante, NASA TM-83000, (1983)

15. H. M. Ghose, J. Ferrante and F. C. Honecy, NASA TND-100103, (1987)

16. S. V. Pepper and D. H. Buckley, NASA TND-6497, (1971)

17. W. R. Jones and J. Ferrante, ASLE Trans. 26, 351 (1983)

18. W. A. Brainard and D. R. Wheeler, J. Vac. Sci. Tech 15, 1800 (1978)

19. T. Spalvins, J. Vac. Sci Tech A 5, 212 (1987)

20. S. V. Pepper, J. Appl. Phys. 45, 2947 (1974)

21. C. M. Pooley and D. Tabor, Proc. Roy. Soc. A 329, 251 (1972)

22. W. R. Jones and W. F. Hady, Wear 70, 77 (1981)

23. D. R. Wheeler, J. Appl. Phys. 47, 1123 (1976) 
24. S. V. Pepper, J. Appl. Phys. 50, 8062 (1982)

25. S. V. Pepper, J. Vac. Sci. Tech. 20, 643 (1982)

26. S. V. Pepper, J. Appl. Phys 47, 2579 (1976)

27. K. Miyoshi and D. H. Buckley, Wear 110, 295 (1986)

28. J. Ferrante and J. R. Smith Phys. Rev. B 31, 3427 (1985)

29. J. R. Smith, J. G. Gay and F. J. Arlinghouse, Phys. Rev B 21, 2201 (1980)

30 J. H. Rose J. R. Smith and J. Ferrante, Phys. Rev. B 28, 1835 (1983)

31. N. W. Ashcroft and N. D. Mermin, Solid State Physics, Holf, Rinehart and Winston, New York, 1976

32. D. R. Clarke and D. Wolf, Mat. Sci. and Eng. 83, 197 (1986)

33. J. R. Smith and J. Ferrante, Phys. Rev. B 34, 2238 (1986)

34. P. D. Bristowe and A Brokman, Acta Metall. 29, 1703 (1981)

35. A. Yaniv, Phys. Rev. B 17, 3904 (1978)

36. G. Allan, M. Lannoo and L. Dobrzynski, Phil. Mag. 30, 33 (1974)

37. C. C. Pei, Phys. Rev. B 18, 2583 (1978)

38. M. L. Payne, P. D. Bristowe and J. D. Johannapoulis, Phys. Rev. Lett., 1348 (1987)

39. D. P. Vincenzo, D. L. Alehand, M. Schluter and J. W. Wilkins Phys. Rev. Lett. 56. 1925 (1986)

40. R. E. Thompson and D. J. Chadi, Phys. Rev. B 29, 889 (1984)

41. R. Car and M. Parrinello, Phys. Rev. Lett 55, 2471 (1985)

42. S. M. Foiles, M. I. Baskes and M. S. Daw, Phys. Rev. B 33, 7983 (1986)

43. J. R. Smith and A. Banerjea, Phys. Rev. Lett. 59, 2451 (1987)

44. J. R. Smith and A Banerjea, J. Vac. Sci. Tech. A 6, 812 (1988)

45. U. Landman and D. L Luditke, Final Program 35th National Symposium of the American Vacuum Society, Abstract TC3-MoA4, p. 61 (1988) 
TABLE I. - METALLIC TRANSFER FOR

DISSIMILAR METALS IN

\section{SLIDING CONTACT}

\begin{tabular}{|c|c|c|}
\hline Disk & Rider & $\begin{array}{c}\text { Transfer of metal } \\
\text { from rider to disk }\end{array}$ \\
\hline Tungsten & Iron & Yes \\
& Cobalt & Yes \\
Tantalum & Yes \\
& Nickel & No \\
& Cobalt & No \\
Molybdenum & Yes \\
& Nickel & No \\
& Cobalt & No \\
& Yros \\
& Niobium & Nickel \\
& Cobalt & No \\
& & No \\
& & Yes \\
\hline
\end{tabular}

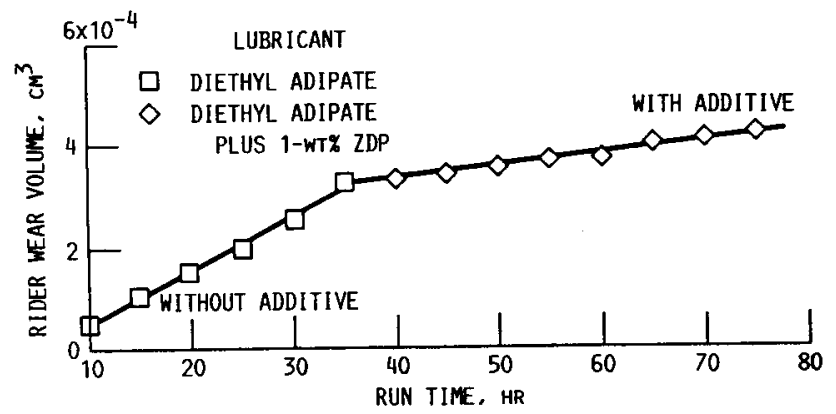

FIGURE 2. - TYPICAL RIDER WEAR VOLUME VERSUS SLIDING TIME CURVE SHOWING RUN-IN AND STEADY-STATE WEAR REGIONS. IN THIS CASE THE RUN IN WAS DONE WITHOUT THE ADDITIVE TO EMPHASIZE THE EFFECT OF THE ADDITIVE.

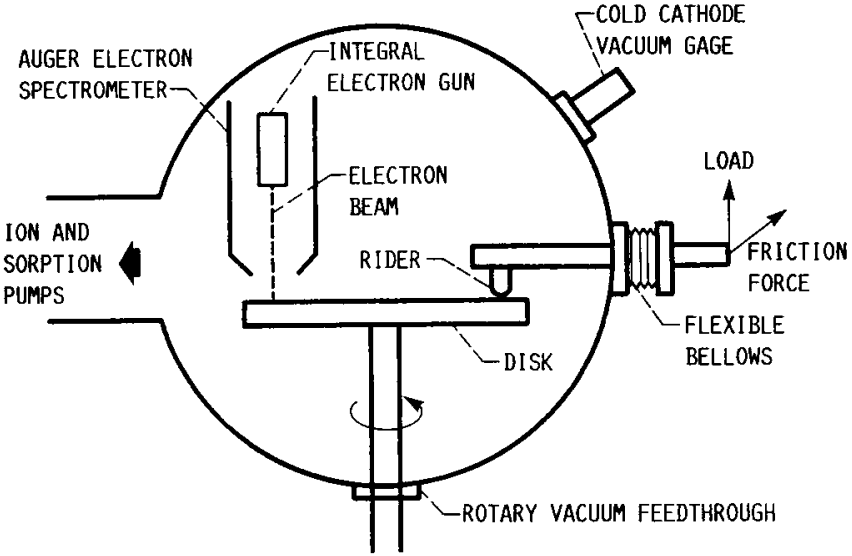

FIGURE 1. - EXPERIMENTAL PIN ON DISK APPARATUS WITH AUGER ELECTRON SPECTROMETER.

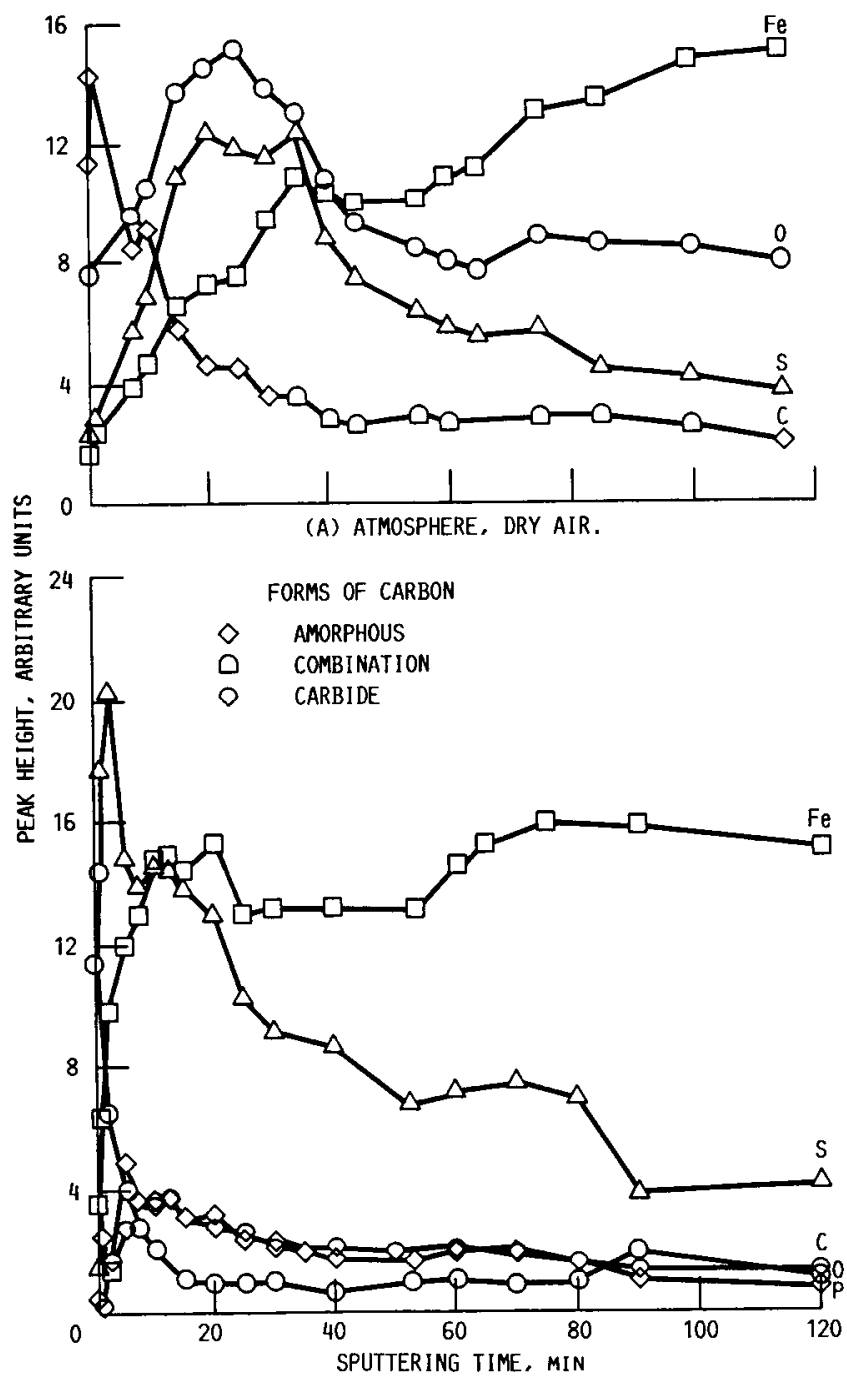

(B) ATMOSPHERE, DRY NITROGEN.

FIGURE 3. - A DEPTH PROFILE OF THE WEAR SCAR ON AN IRON PIN RUN IN TWO AMBIENT ATMOSPHERES WITH DIBUTYL SEBACATE AS THE LUBRICANT AND 1.0 WEIGHT PERCENT ZDDP AS THE ADDITIVE IN THE BOUNDARY LUBRICATION REGION. 


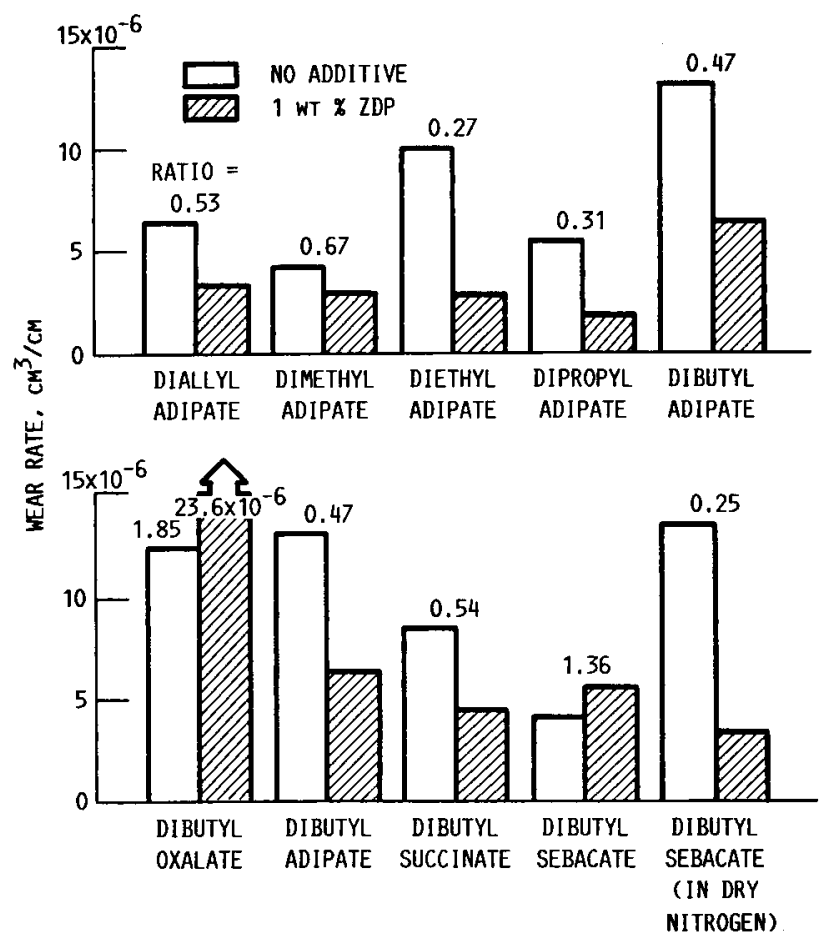

FIGURE 4. - WEAR RATES WITH AND WITHOUT ADDITIVE FOR A NUMBER OF LUBRICANT BASE STOCKS.
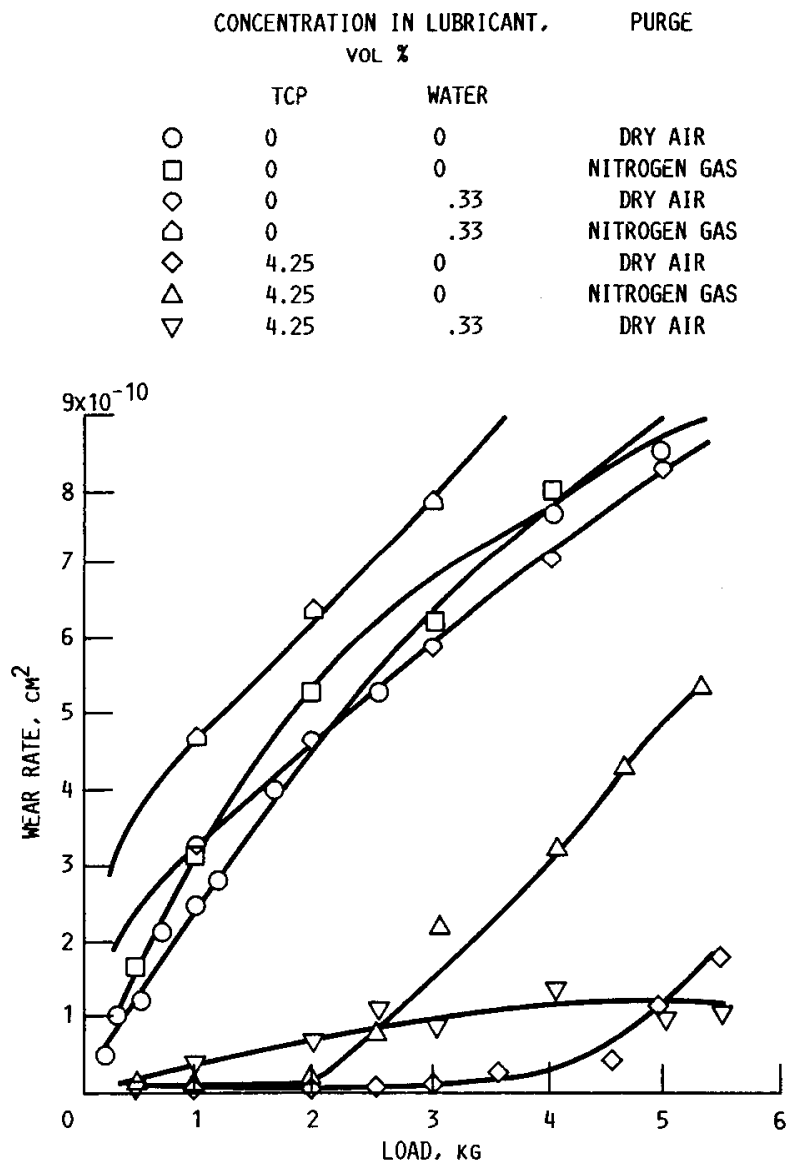

FIGURE 5. - STEP LOADING WEAR RATE VERSUS LOAD WITH AND WITHOUT TCP FOR VARYING AMBIENT CONDITIONS. 


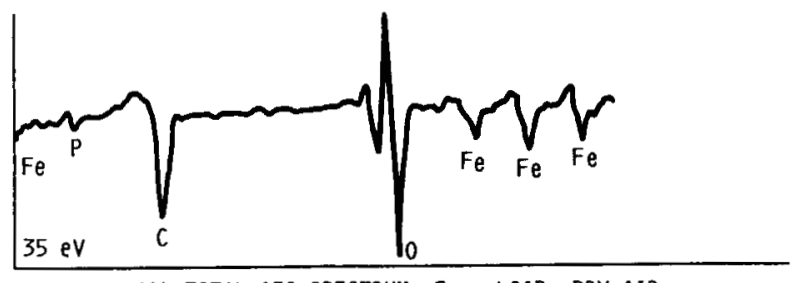

(A) TOTAL AES SPECTRUM; 5-KG LOAD: DRY AIR.

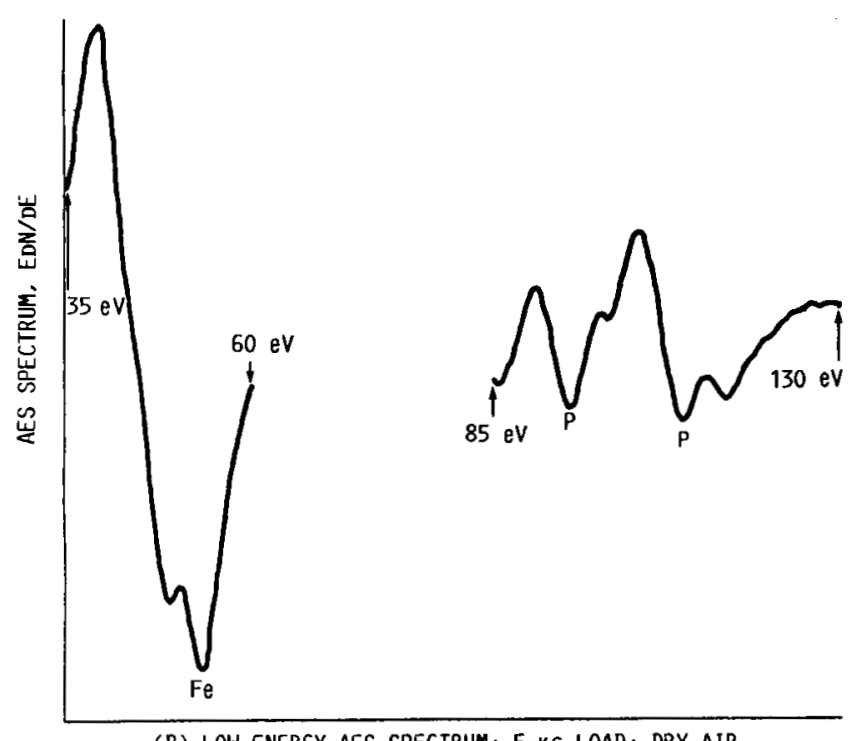

(B) LOW-ENERGY AES SPECTRUM: 5-KG LOAD; DRY AIR.

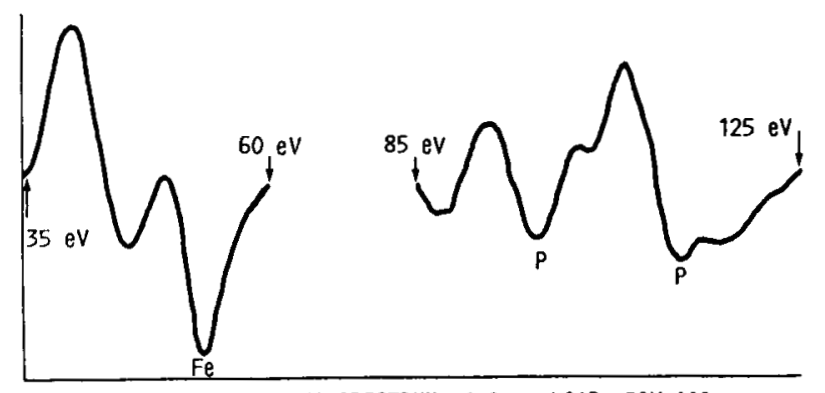

(C) LOW-ENERGY AES SPECTRUM: 1.2-KG LOAD, DRY AIR.

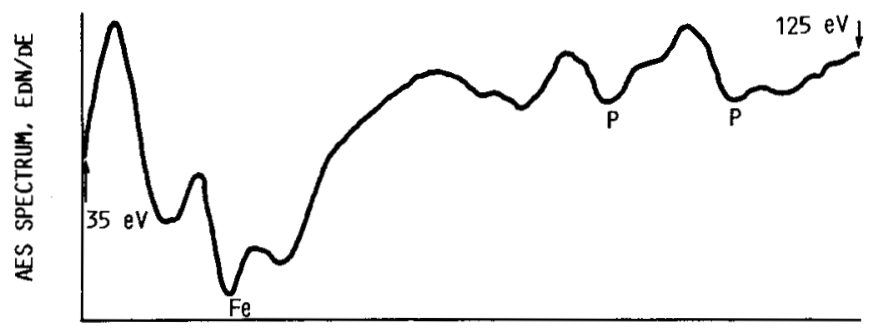

(D) LOW-ENERGY AES SPECTRUM: 1.2-KG LOAD: DRY NITROGEN.

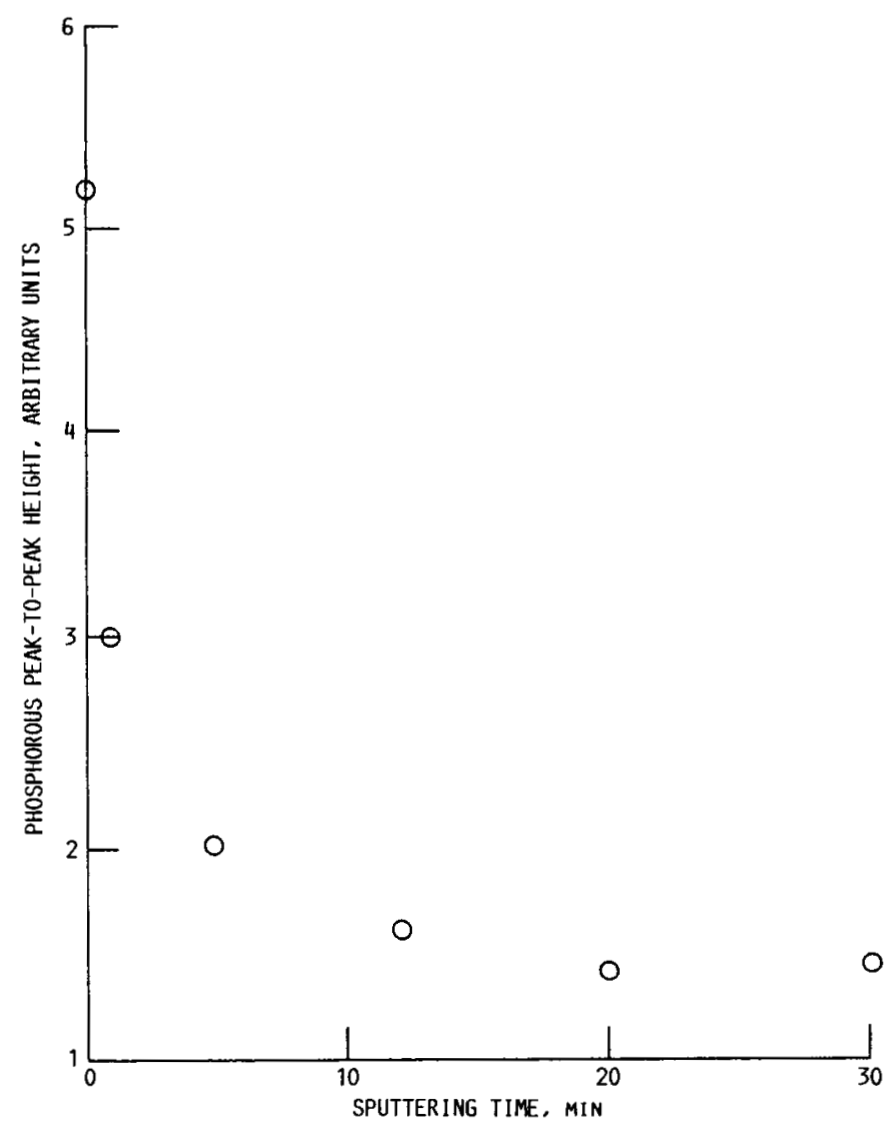

(E) AES DEPTH PROFILE OF THE SPECTRUM FROM 21(C).

FIGURE 6. - TOTAL AND LOW-ENERGY AES SPECTRA OF A LUBRICANT WITH TCP ADDITIVE UNDER TWO DIFFERENT LOADS IN TWO DIFFERENT ATMOSPHERES WITH A DEPTH PROFILE FROM FIG. 6C. 


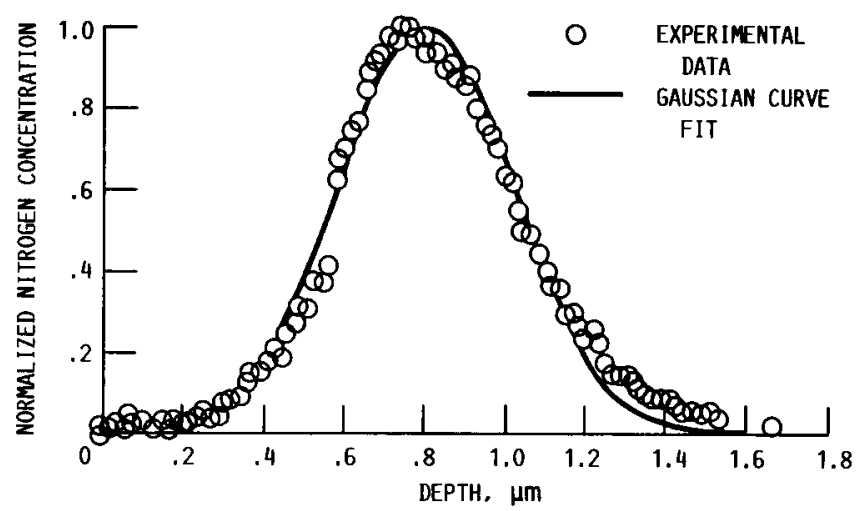

FIGURE 7. - NITROGEN CONCENTRATION AS A FUNCTION DEPTH IN A NITROGEN IMPLANTED STEEL DISK. WEAR WAS REDUCED BY 40 PERCENT IN THE RUN-IN RANGE AND BY 20 PERCENT IN THE STEADYSTATE RANGE.

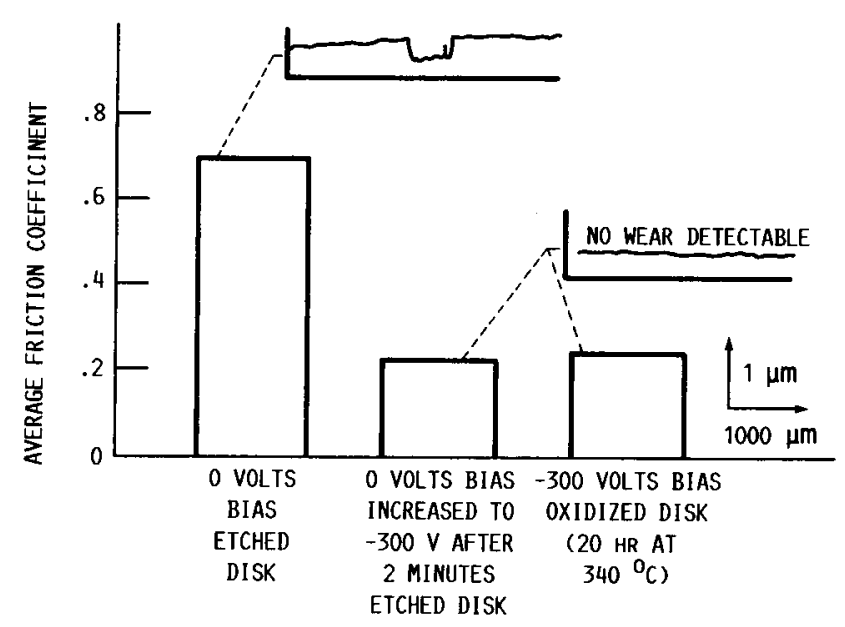

(A) AVERAGE FRICTION COEFFICIENT AND COATING WEAR TRACES FOR $\mathrm{rf}$ SPUTTERED $\mathrm{MO}_{2} \mathrm{C}$ ON 440-C DISK; 304 RIDER: $0.10 \mathrm{~N}$ LOAD; $\mathrm{N}_{2}$ ATMOSPHERE.
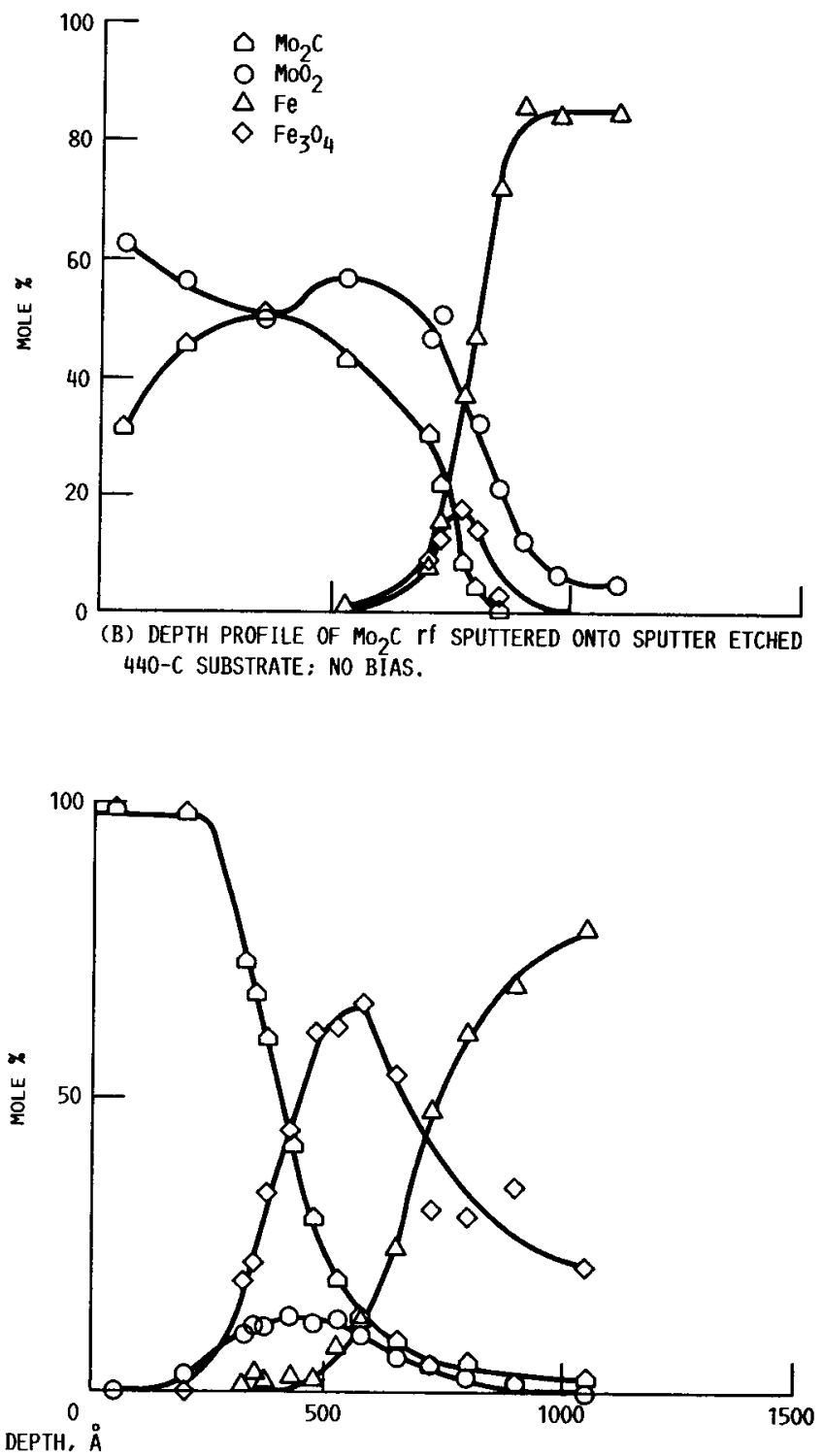

(D) DEPTH PROFILE OF MO $\mathrm{C}_{2} \mathrm{rf}$ SPUTTERED ONTO AN OXIDIZED 440-C SUBSTRATE, $-300 \mathrm{~V}$ BIAS.
(C) DEPTH PROFILE OF $\mathrm{MO}_{2} \mathrm{C} \mathrm{rf}$ SPUTTERED ONTO A SPUTTER ETCHED 440-C SUBSTRATE WITH $-300 \mathrm{~V}$ BIAS.
FILM DEPTH,

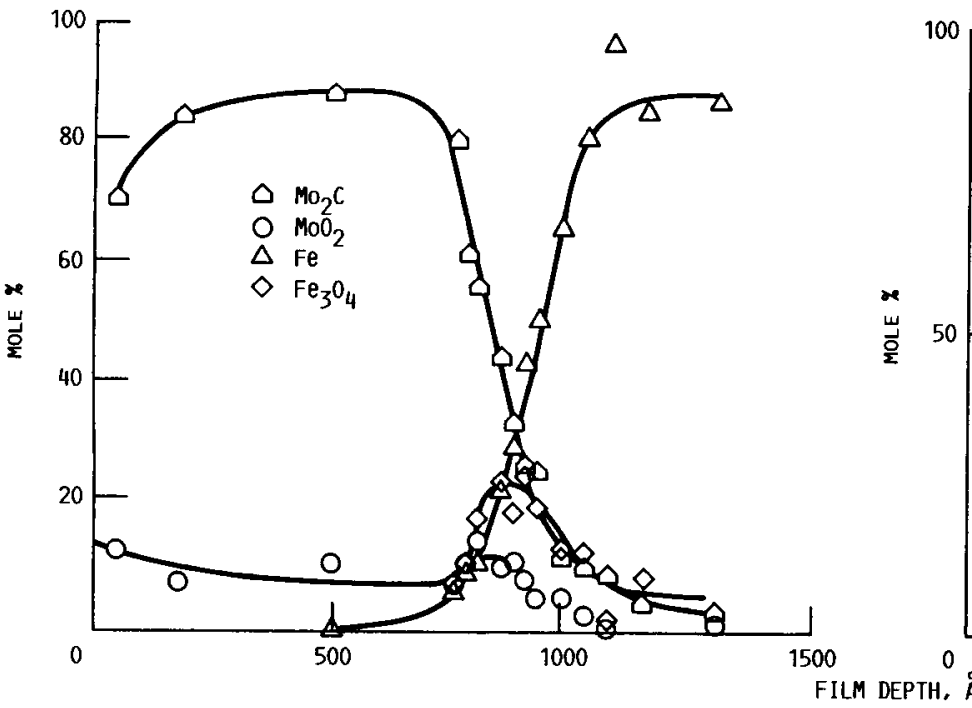

FIGURE 8. - FRICTION AND WEAR OF A MO ${ }_{2} \mathrm{C}$ SPUTTER COATED 440-C DISK UNDER VARYING DEPOSITION CONDITIONS. 

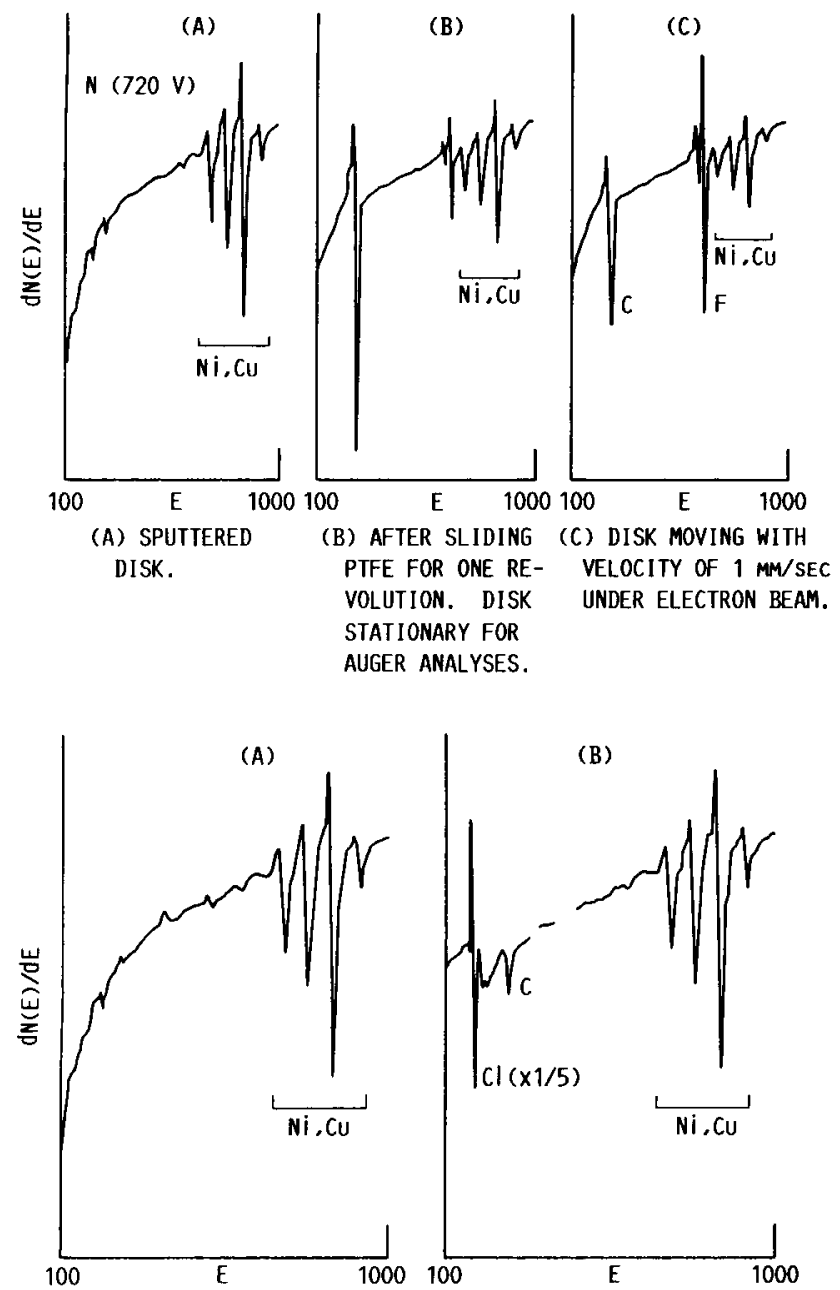

(A) SPUTTERED DISK.

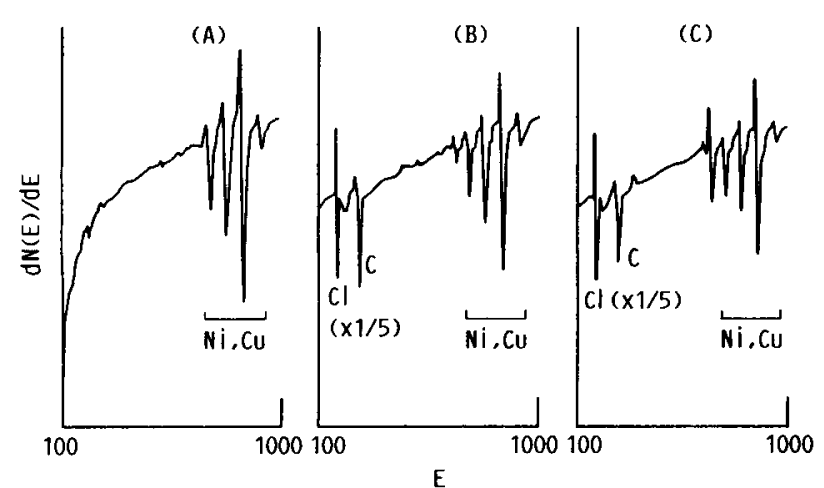

(A) SPUTTERED DISK. (B) AFTER SLIDING (C) DISK MOVING WITH PCTFE FOR ONE VELOCITY OF $1 \mathrm{MM} / \mathrm{SEC}$ REVOLUTION. DISK STATIONARY FOR AUGER ANALYSES.

FIGURE 9. - AES SPECTRA FROM AN S-MONEL DISK WITH TRANSFER FILMS FROM DIFFERENT POL YMERS.

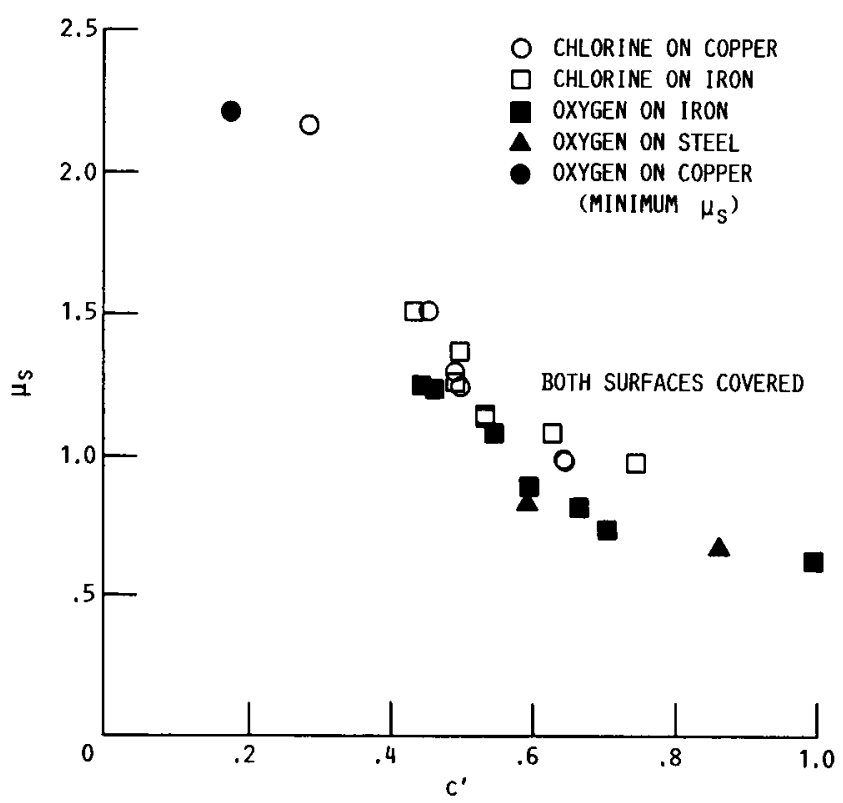

(A) STATIC COEFFICIENT OF FRICTION $\mu_{S}$ AS A FUNCTION OF ADSORBATE CONCENTRATION. $c^{\prime}$.

FIGURE 10. - EFFECTS OF OXYGEN AND CHLORINE ADSORPTION ON STATIC FRICTION FOR A METAL-METAL CONTACT.

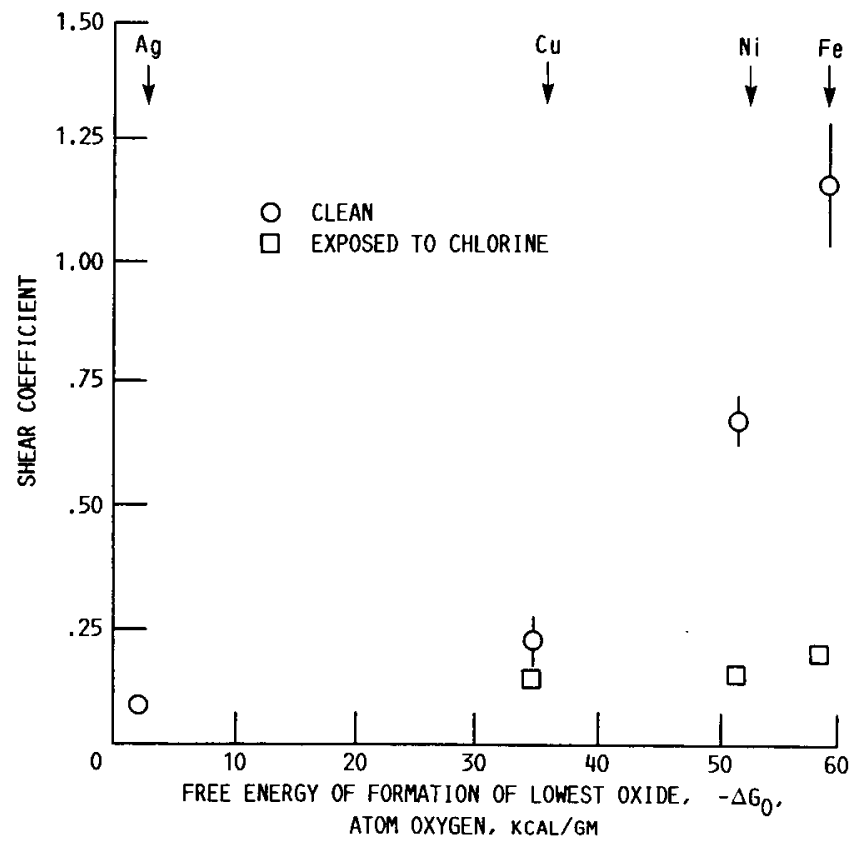

FIGURE 11. - SHEAR COEFFICIENTS OF CLEAN AND CLORINATED METALS IN CONTACT WITH CLEAN (0001) SAPPHIRE PLOTTED VERSUS FREE ENERGY OF OXIDE FORMATION OF THE LOWEST METAL OXIDE. THE MEAN DEVIATION IS INDICATED BY THE VERTICAL BARS. 


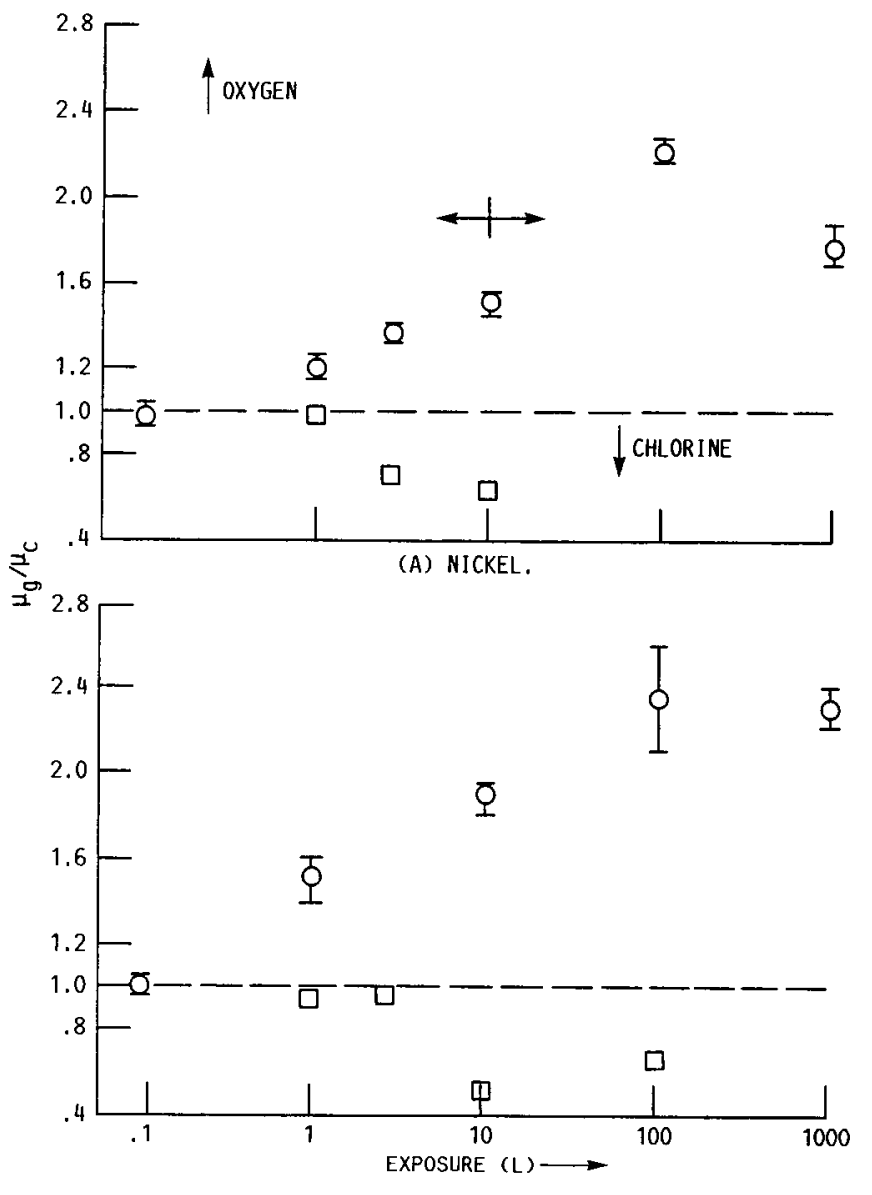

(B) COPPER.

FIGURE 12. - RATIO OF STATIC FRICTION COEFFICIENT AFTER EXPOSURE TO GAS $\mu_{g}$ TO STATIC FRICTION COEFFICIENT OF CLEAN CONTACT $\mu_{c}$ PLOTTED AGAINST EXPOSURE TO OXYGEN AND CHLORINE.

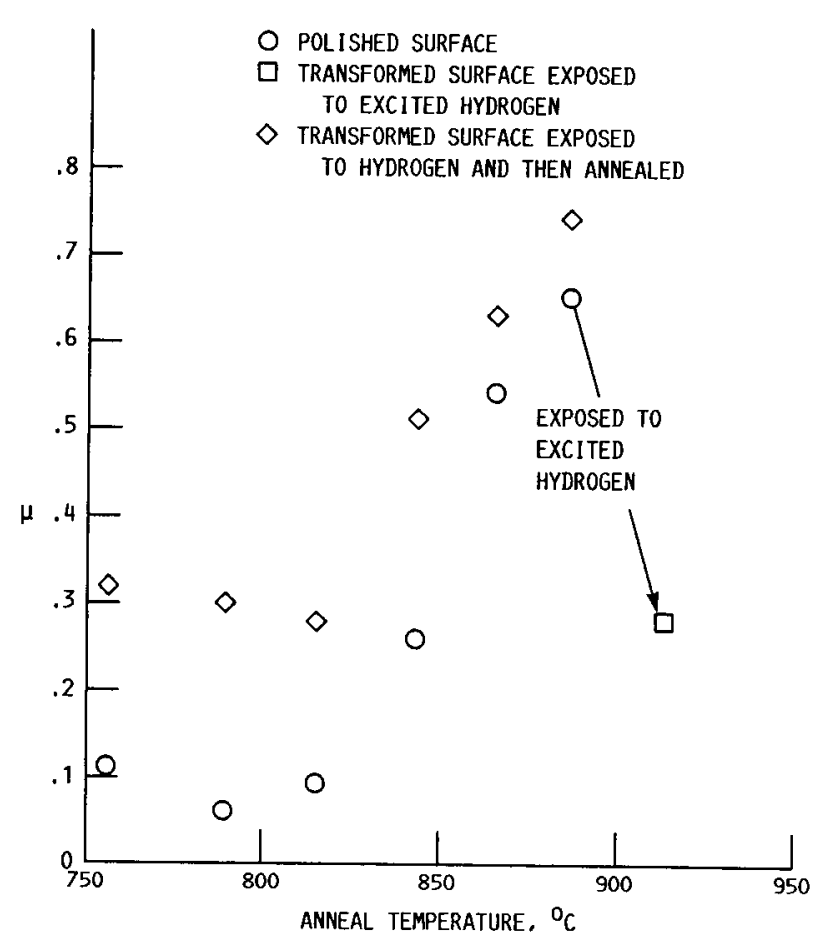

FIGURE 13. - COPPER-DIAMOND STATIC FRICTION COEFFICIENT AS A FUNCTION DIAMOND AMNEAL ING TEMPERATURE. 


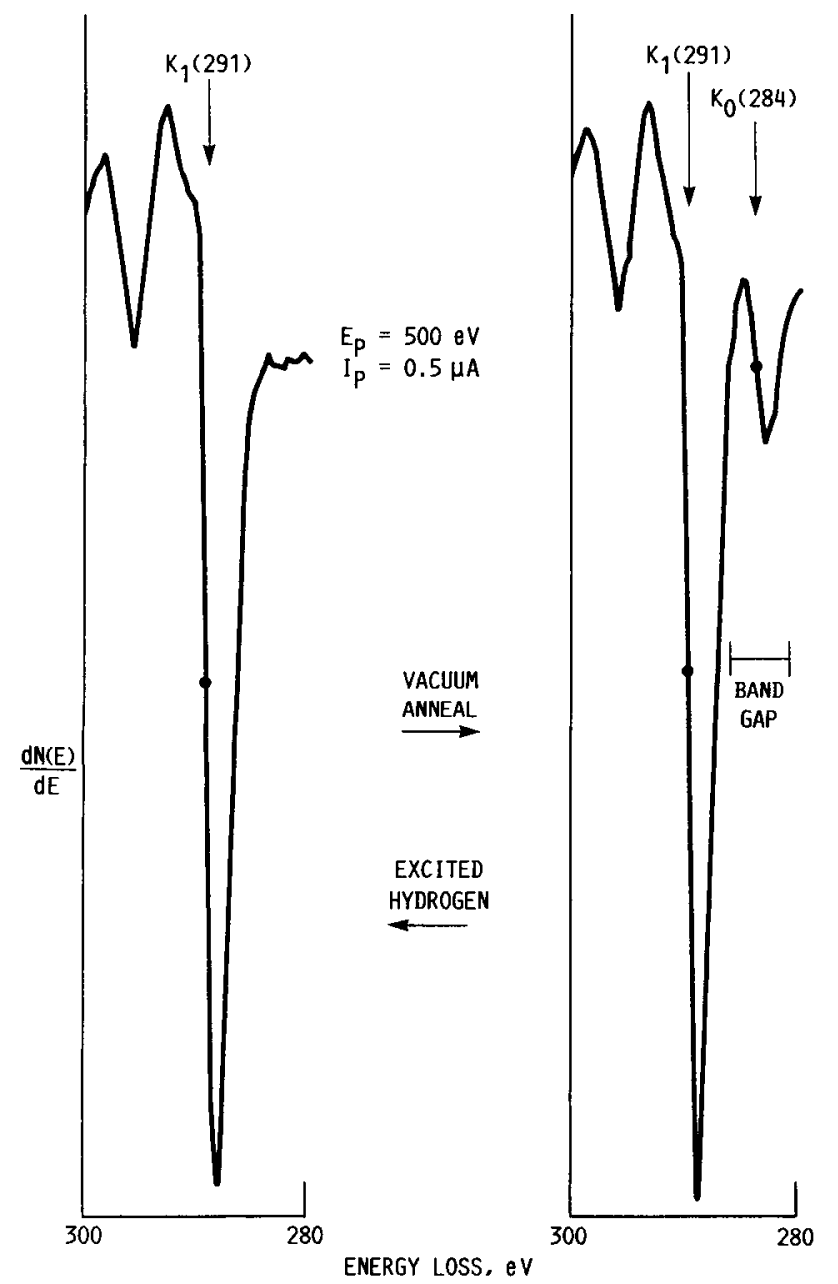

(A) SURFACE IS EITHER FRESHLY POLISHED OR EXPOSED TO EXCITED HYDROGEN.
(B) DIAMOND HAS BEEN ANNEALED AT $\sim 900{ }^{\circ} \mathrm{C}$ TO DEVELOP $\mathrm{K}_{0}$ TO ITS MAXIMUM SIZE OF $0.14 \mathrm{~K}_{1}$.

FIGURE 14. - CORE-LEVEL IONIZATION LOSS SPECTRA OF DIAMOND (110).

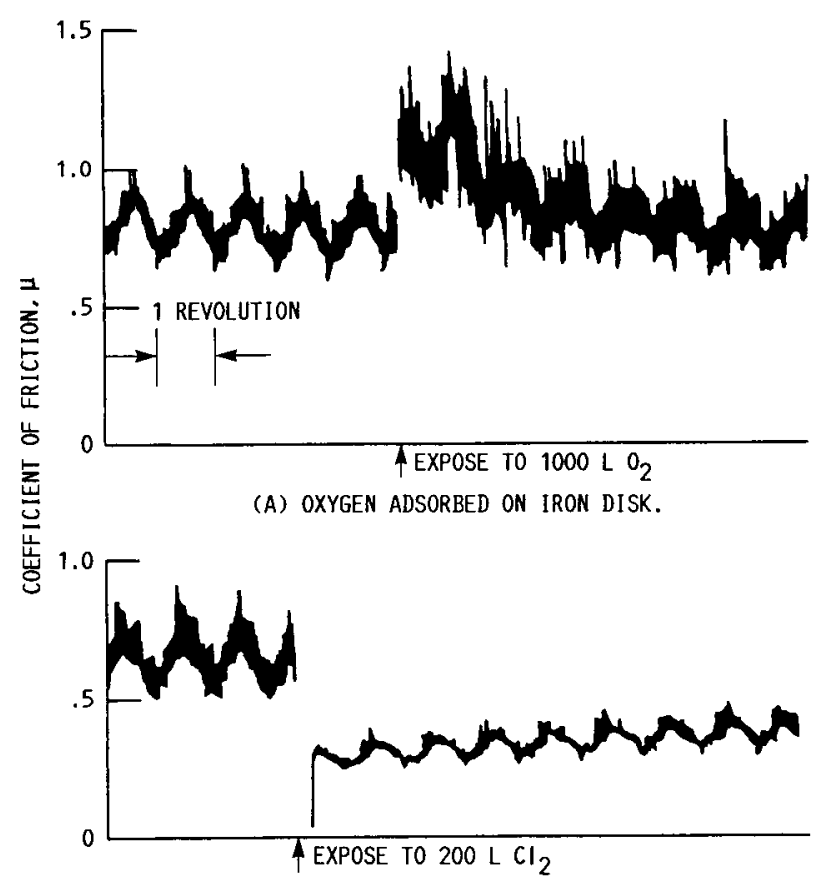

(B) CHLORINE ADSORBED ON IRON DISK.

FIGURE 15. - EFFECT OF OXYGEN AND CHLORINE ON THE DYNAMIC FRICTION OF FE SLIDING ON SAPPHIRE. 


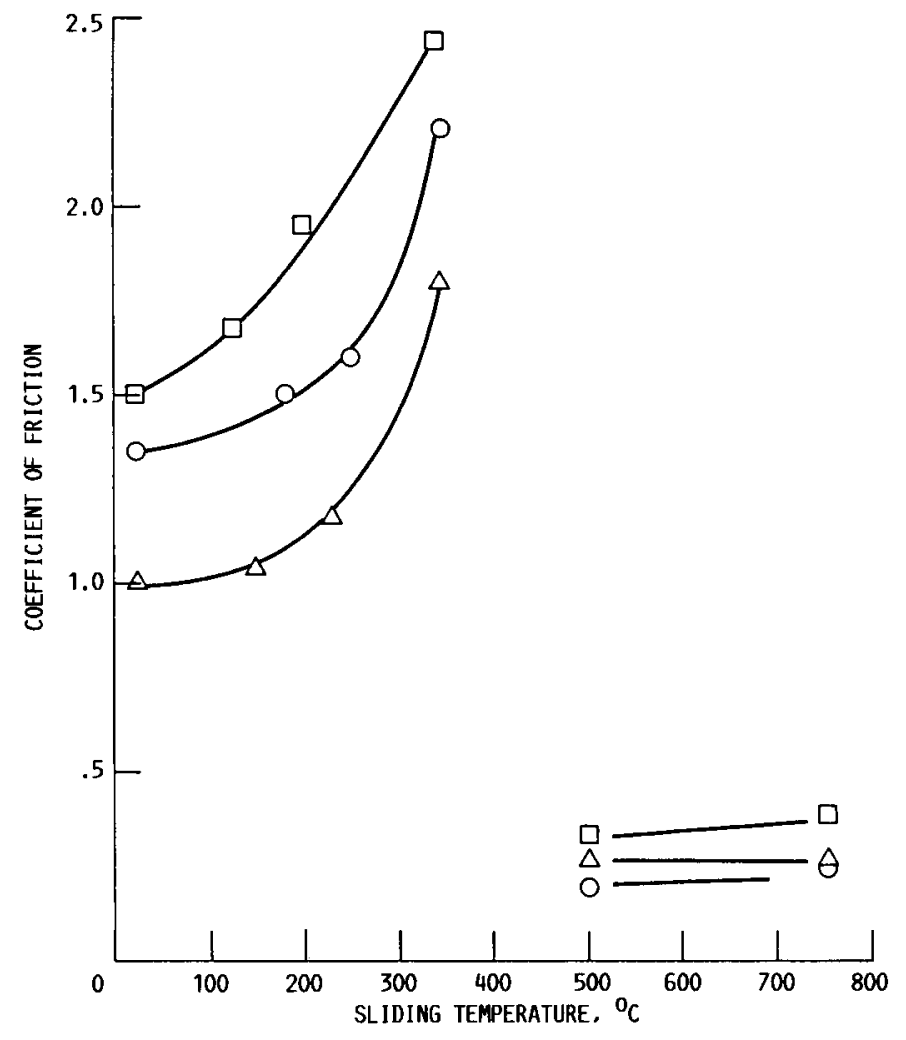

FIGURE 16. - COEFFICIENT OF FRICTION AS A FUNCTION OF TEMPERATURE FOR ALUMINUM OXIDE SLIDING OF 67Fe-18C0-14B-1Si (O), 81Fe-13.5B$3.5 \mathrm{Si}-2 \mathrm{C} \triangle \triangle$ AND 40Fe-38Ni-4MO-18B ( $\square$ ) AMORPHOUS ALLOYS IN VACUUM.
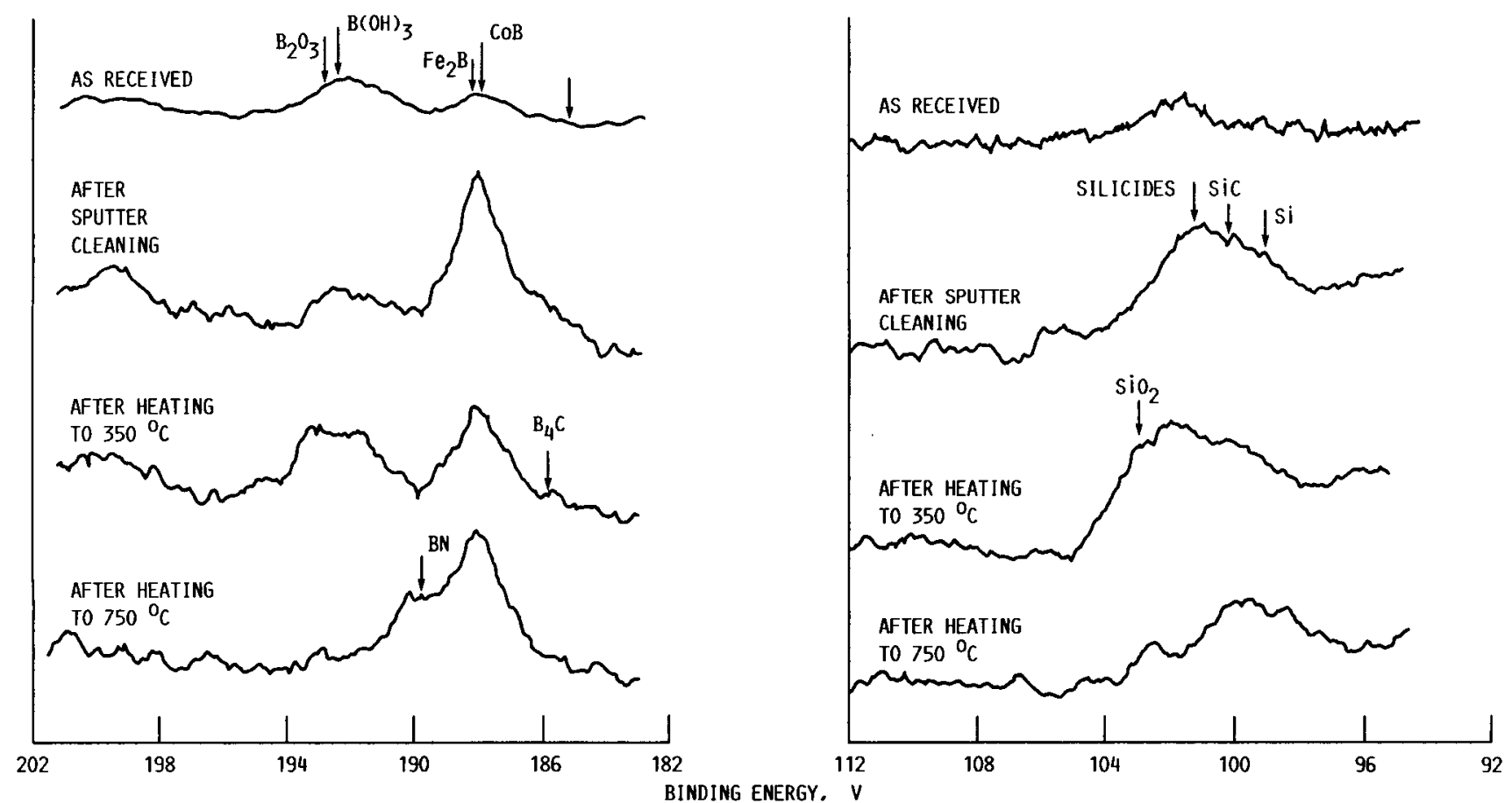

(A) B 1s.

(B) Si $2 p$.

FIGURE 17. - REPRESENTATIVE XPS PEAKS OF A 87Fe-18C0-148-1Si AMORPHOUS ALLOY SURFACE. 

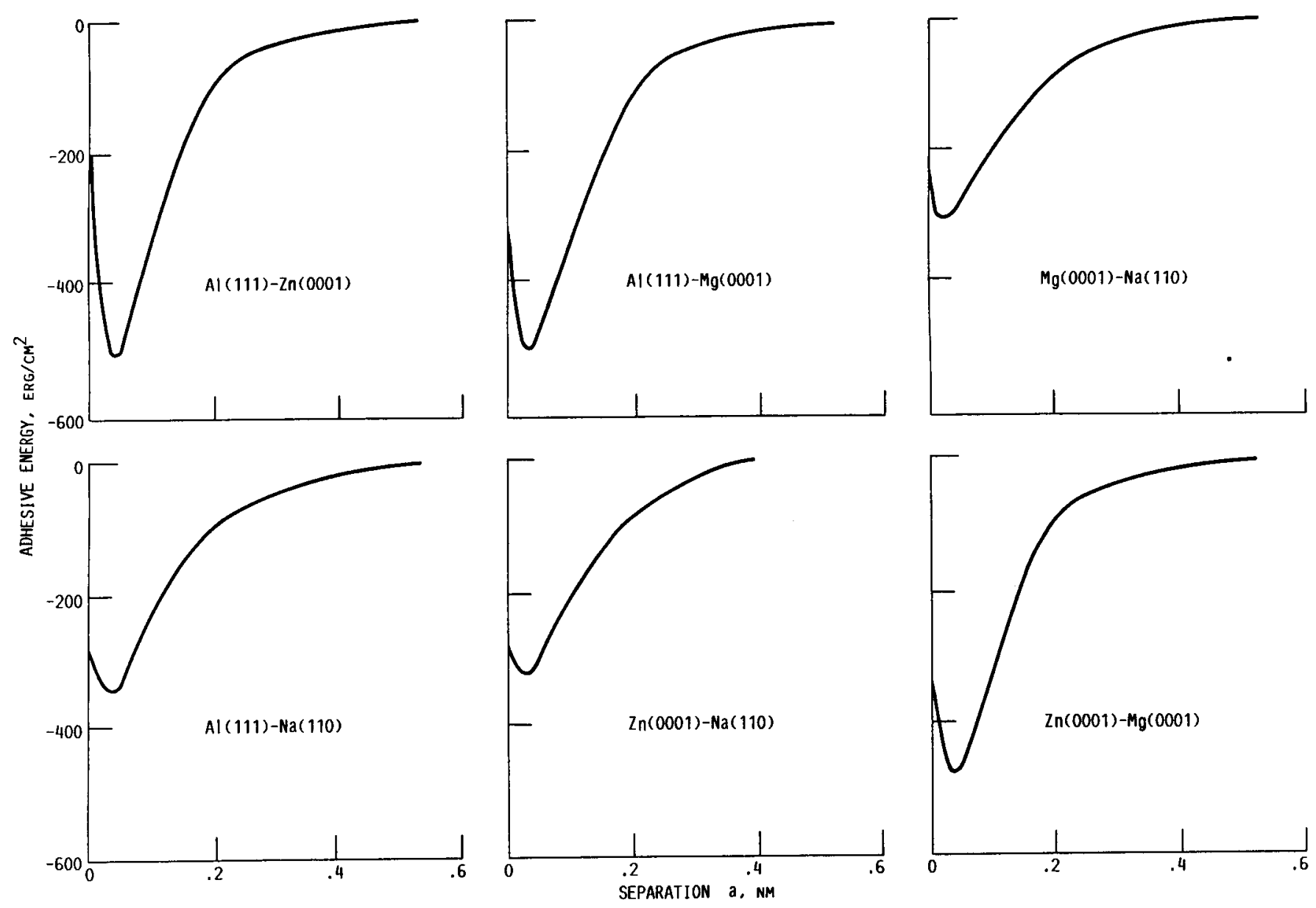

FIGURE 18. - ADHESIVE BINDING ENERgY VERSUS SEPARATION, a, BETWEEN METALS. 


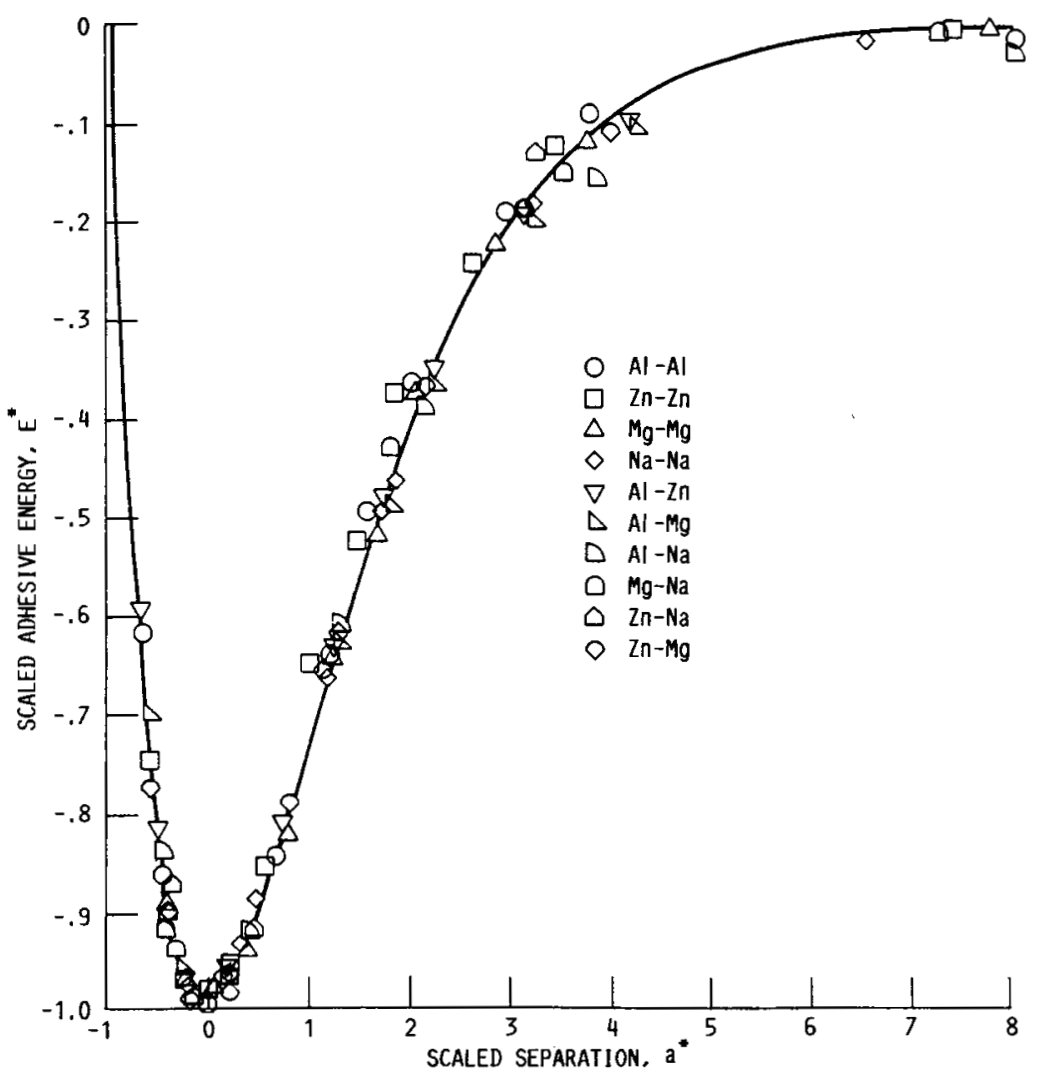

FIGURE 19. - SCALED ADHESIVE BINDING ENERGY AS A FUNCTION OF SCALED SEPARATION. 


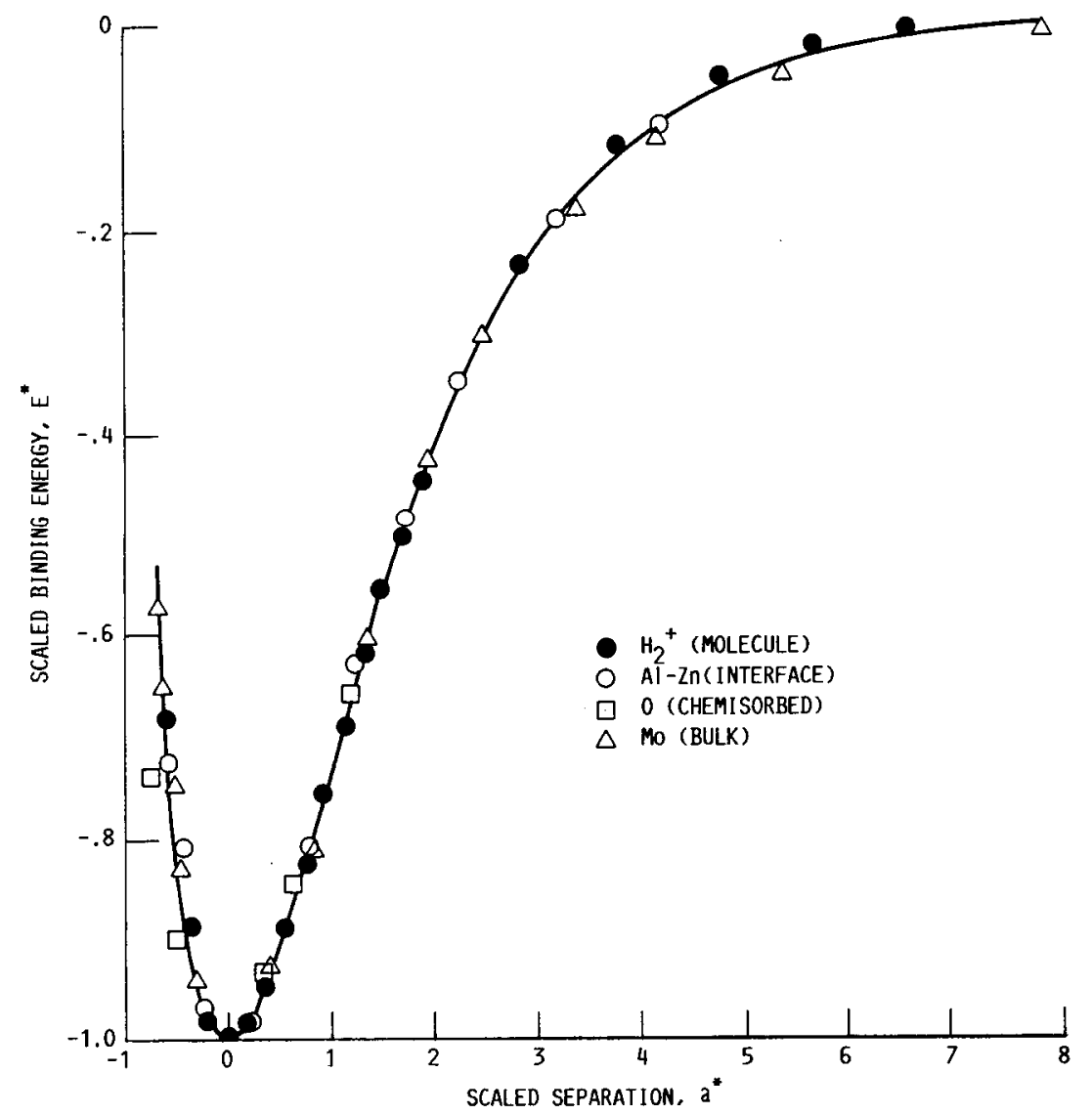

FIGURE 20. - SCALED BINDING ENERGY AS A FUNCTION OF SCALED INTERATOMIC SEPARATION FOR FOUR DIFFERENT TYPES OF BINDING. 


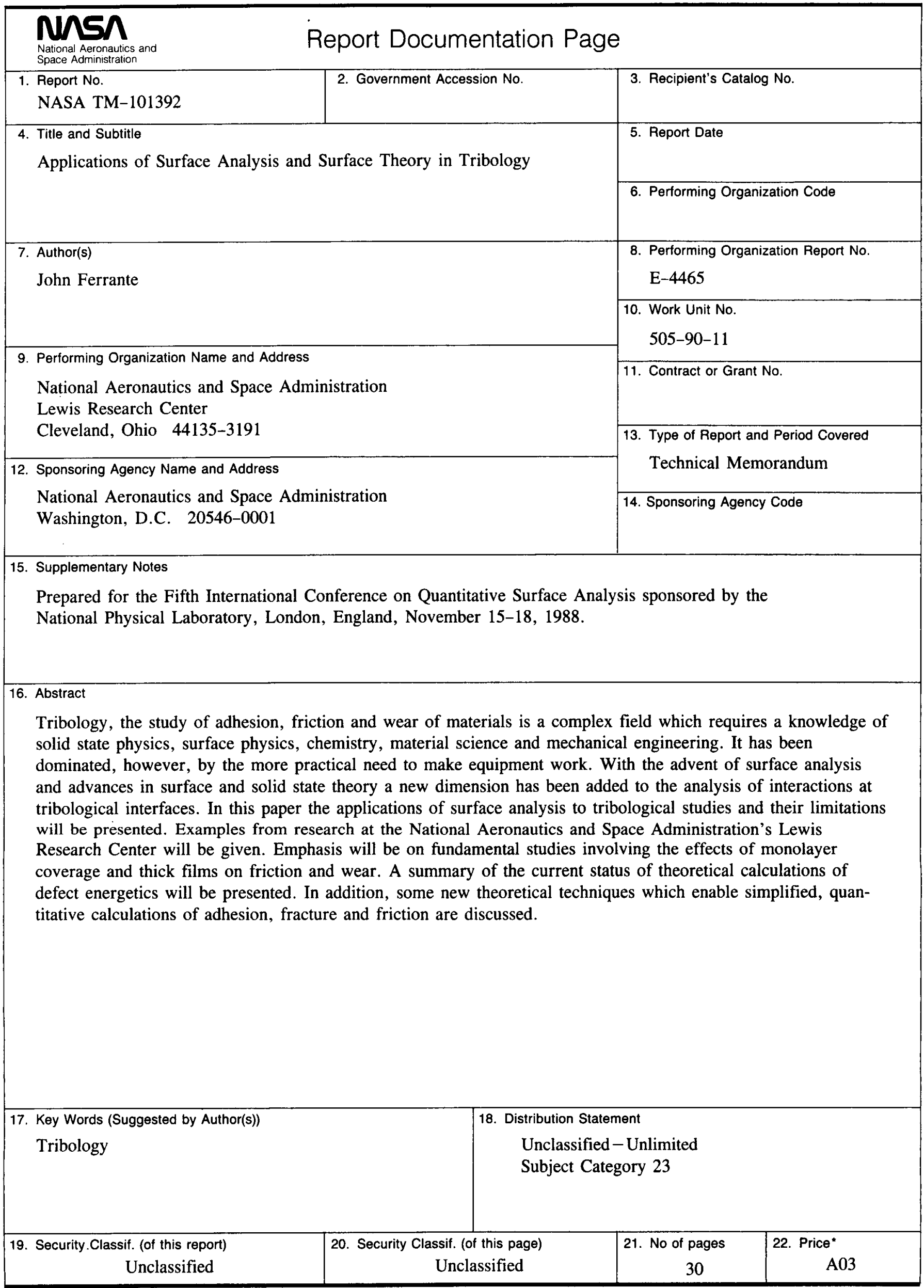

